\title{
Draft Safety Review Plan for Accelerator Production of Tritium (APT) Project
}

\author{
LMITCO/AEDL \\ DOE DP-61 Office of Accelerator Production \\ DOE DP-45 Technical and Environmental Support \\ AMPARO
}

Published July 1997

Idaho National Engineering and Environmental Laboratory

Advanced Nuclear Energy Products

Lockheed Martin Idaho Technologies Company

Idaho Falls, Idaho 83415

\author{
Prepared for the \\ U.S. Department of Energy \\ Assistant Secretary of Energy \\ Defense Programs \\ Under DOE Idaho Operations Office \\ Contract DE-ACO7-941013223
}

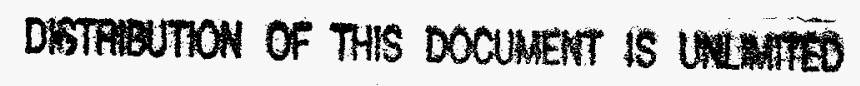

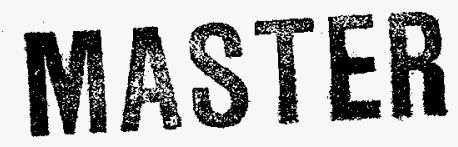




\section{DISCLAIMER}

This report was prepared as an account of work sponsored by an agency of the United States Government. Neither the United States Government nor any agency thereof, nor any of their employees, makes any warranty, express or implied, or assumes any legal liability or responsibility for the accuracy, completeness, or usefulness of any information, apparatus, product, or process disclosed, or represents that its use would not infringe privately owned rights. Reference herein to any specific commercial product, process, or service by trade name, trademark, manufacturer, or otherwise does not necessarily constitute or imply its endorsement, recommendation, or favoring by the United States Government or any agency thereof. The views and opinions of authors expressed herein do not necessarily state or reflect those of the United States Government or any agency thereof. 


\section{DISCLAMMER}

Portions of this docoment misy be illegible in electronic image prodnetc. Images are produced from the best available original docement. 
This document responds to the requirement for an Accelerator Production of Tritium (APT) Safety Review Plan (SRP) established under Task 1 of DOE-DP-6I Project: Financial Information Number (FIN) 4 AA200. 


\section{CONTENTS}

1. Purpose ........................ 1

2. Anticipated Products ........... 2

3. Interfaces with Other APT Development Activities . . . . . . . 3

4. Assumptions .................. 5

5. Technical Approach to the PSAR Review . . . . . . . . . . . . 10

6. PSAR Reviews and Assignments .................. 11

6.1 Review Team Organization ................... 11

6.2 Documentation of Comments ................. 16

6.2 .1 Level of Comments ..................... . . 16

6.2.2 Format and Contents of Comments . . . . . . . . . . . . . 16

6.3 Review Criteria . . . . . . . . . . . . . . . . . 19

6.4 PSAR Review Criteria .................... 23

6.4.1 Accident Analysis . . . . . . . . . . . . . . . . . . . 23

6.4.2 Site Characteristics and Cleanup Chapters ............ . 32

6.4.3 Programmatic Chapters ..................... . 37

7. SER Preparation and Assignments . . . . . . . . . . . . . 48 48

7.1 SER Preparation Team Organization ................48

7.2 Process for Identifying SER Issues . . . . . . . . . . . . 49

7.3 Acceptance Criteria to be Used in the SER ..............49

7.4 SER Preparation, Review, and Approval Process . . . . . . . . . . . 50

7.5 Quality Assurance Requirements for the Preparation of the SER . . . . 50

7.6 SER Content and Format Guidance . . . . . . . . . . . . . . . 50

8. Milestone Schedule ... . . . . . . . . . . . . 54

9. Profiles of PSAR Review and SER Preparation Participants . . . . . 54

10. Record Keeping .................... . 55

11. Reports . . . . . . . . . . . . . . . . . 58

11.1 Meeting Minutes . . . . . . . . . . . . . . . . . 58

11.2 Formal Technical Evaluations . . . . . . . . . . . . . . 58

11.3 Informal Technical Evaluations ................... 59

11.4 Periodic Progress Reports . . . . . . . . . . . . . . . . . . . 59

11.5 Draft SER . . . . . . . . . . . . . . . . . 60

12. References ................61

Figures

3-1 Independent Safety Review Interfaces ..............6 6

6-1 Lockheed Management Structure ................. 15

6-2 Comment/Resolution Form . . . . . . . . . . . . 17

Tables

6.1 Independent Review Team . . . . . . . . . . . . . . 12

8-1 Milestone Schedule ................... . . 55

Attachment

1 Independent Review Process ............... A-1 


\section{Purpose}

\section{APT Safety Review Plan}

The purpose of this "living" Safety Review Plan (SRP) is to describe the products and processes that will be followed to conduct a systematic review of the Accelerator Production of Tritium (APT) Facility Preliminary Safety analysis Report (PSAR), and subsequently to prepare a draft Safety Evaluation Report (SER) on the PSAR. This plan is prepared for and will be implemented by the APT Independent Safety Review Committee (ISRC) over the period July 1 , 1997 through September 30, 1998, in accordance with provisions established in DOE-STD-1104-96.

The ISRC is staffed by teams of Department of Energy (DOE), Idaho National Engineering and Environmental Laboratory (INEEL), and AMPARO Corporation engineers and scientists. The ISRC will operate on three levels. A Top-Leve1 "Review Team" made up of a total of three representatives, one each from the INEEL, DOE-Defense Programs Office of Special Projects (DP-45), and DOE Office of Accelerator Production (DP-61), will interface directly with PSAR preparers and will screen ingoing and outgoing material submitted for review in accordance with guidelines established in Section 6.3 of this SRP. Mid-Level "Team Leaders" are identified for each chapter of the PSAR and are responsible for organizing the review, assembling comments, and submitting them to the Review Team for out-screening to the PSAR preparers. Work-Level "Reviewers" are responsible for doing the reviews in accordance with criteria established in Section 6.4 of this SRP. Individual ISRC staff may perform at more than one work level.

A core team of DOE, INEEL, and AMPARO Corporation engineers and scientists will prepare the initial draft SER with assistance from other ISRC team members on an as needed basis. Guidelines for preparing the draft SER are presented in Section 7 of this SRP.

The PSAR reviews will focus exclusively on safety. The ever-present two-part question will be: Does the subject matter have safety significance? If so, does the APT structural, system, component, and/or process engineering design ensure an acceptable margin of safety? The APT mission, efficiency, and cost are not considerations of this plan. A more detailed discussion of the review philosophy is presented in Section 5 of this SRP.

The remaining Sections 2 through 12 of this SRP present discussions of 
the ISRC:

- products,

- interfaces with non-ISRC participants,

- assumptions made to conduct the PSAR review and prepare a draft SER,

- technical approach to safety,

- PSAR review criteria,

- $\quad$ SER preparation guidelines,

- a milestone schedule,

- reviewer/preparer profiles,

- record keeping,

- reports, and

- references.

\section{Anticipated Products}

There will be five types of products developed by the ISRC during implementation of this SRP. These products are summarized here and described, in detail, in Section 11 of this SRP.

- Comments on the integrated PSAR, individual chapters, and individual sections within chapters formatted in accordance with guidelines established in Section 6.2 of this SRP. These comments will reflect criteria drawn from DOE-STD-3009-94, Savannah River guidelines implementing DOS-STD-3009-94, and APR Safety Implementation PIan (SIP) and described in Section 6.4 of this SRP.

- Analysis results and findings on subject matter contained in the PSAR and determined to require confirmatory analysis to resolve 
potential and real comments. These analyses will be conducted to the extent possible by members of the ISRC.

- One or more formal Technical Evaluation Reports (TER) codifying the ISRC review of the PSAR.

- Draft SER prepared in accordance with guidelines established in Section 7 of this SRP.

- $\quad B i-m o n t h l y$ progress reports in accordance with guidelines established in Section 11.4 of this SRP, describing work accomplished relative to work planned and costs associated with spending schedules and accomplishment of technical milestones.

\section{Interfaces with 0ther APT Development Activities}

The responsibilities of the various groups performing the independent review and the APT development activities is described in this section. The independent review organization under the direction of DOE DP-61 consists of the following;

Independent Safety Review Committee (ISRC)

Review Team is comprised of representatives from the DOE DP-61, the accelerator production program manager; DOE DP-45, the DOE safety support; and INEEL, contractor independent review staff Manager. The specific participants include Eric Schweitzer, DP-61 Lead, Dae Chung, DP-45, and Gerald Dinneen, INEEL. The function of this team is to ensure that the information to be reviewed is complete and sufficient for technical review by the independent review members and the resulting comments generated during the technical review are consistent and complete. Other functions would include the approval of the Safety Review Plan, prepare the draft SER, develop resolution to safety issues from outside reviewers as directed by the APT Program office, and prepare the final SER.

Technical Independent Review is performed by contractor staff support which is performed under the management of the INEEL. The participants include staff members from the INEEL and AMPARO. The INEEL participants provide safety expertise in the following areas: safety analysts; 
therma1/hydraulics modeling; system engineers; shielding; instrumentation and control; criticality; radiation protection; electrical; siting and environmental issues; human factors; risk analysts; decontamination and decommissioning; emergency preparation; facility operations; technical safety requirements; procedures and training; $Q A$; waste handling; industrial hazards; testing, surveillance, and maintenance; and operational safety. The AMPARO participants provide the accelerator technical expertise as well as expertise regarding nuclear data issues for the target/blanket interactions.

DOE Staff Support is provided by DOE DP-45 to assist in the independent review. The participants include DOE staff members that have the following expertise: seismologist, safety analyst, risk analyst, neutron physics, thermal/hydraulics, system engineer, QA specialist.

Interfacing Organizations

APT Program Office consists of a safety review panel composed of DOE representatives that has the ultimate responsibility of accepting the resolution of safety issues and approval of the PSAR. The specific participants include: Eric Schweitzer DP-61, Dae Chung DP-45, Dick Englehart EH-31, DOE SRS safety representative, DOE accelerator safety representative, and DOE DP-20 facility representative. The function of this office is to review and recommend approval of the Safety Review Plan, review the Safety Implementation Plan, review the PSAR, review the draft SER, accept/reject the safety issues and resolutions from outside reviewers, and recommend approval of the PSAR.

APT Project office consists of representatives from the facility designers, Burns and Roe/General Atomics and the Safety Working Group. Mike crane is the lead for this office. The functions of this office is to prepare the Safety Implementation Plan, prepare the Draft PSAR, provide dispositions for the reviewer comments, incorporate changes to the PSAR that result from comment resolutions, prepare the final PSAR.

Defense Nuclear Facility Safety Board (DNFSB) is a review agency established by Congress to oversee the Department of Energy practices at defense nuclear facilities that could adversely affect public health and safety during any stage of the life cycle including design, 
construction, operation and decommissioning. The DNFSB will be involved in the review of the PSAR, identifying safety issues and proposed resolutions, and providing editorial suggestions.

The overall interfaces of these groups during the independent review of the APT PSAR is shown in Figure 3-1.

\section{Assumptions}

In preparing the technical and administrative contents of this SRP, the following assumptions are made.

\section{Genera 1}

1. APT program development from the present through September 30 , 1998 will be guided by DOE regulatory design and safety requirements established by DOE Order 420.1 rather than requirements established by the U.S. Nuclear Regulatory Commission.

2. Design and safety documentation will be available with sufficient lead time for the ISRC team to meet the milestones presented in Section 8 of this SRP.

3. Chapter 4 of the Conceptual Design Report (CDR) summarizes the plant level functions, performance requirements and design criteria.

4. The safety aspects of the APT which were developed during the conceptual design are largely contained in chapter 7 of the CDR. The discussion covers the design criteria, safety features, preliminary hazards analysis, preliminary functional classification, accident analysis, and gives preliminary conclusions for each major subsystem of the Accelerator, Target Blanket, Tritium Separation Facility and the Balance of Plant.

\section{Safety}

5. The APT plant will meet the safety requirements for a plant classified as a non-reactor nuclear facility as defined by DOE Order 5480.23, Nuclear Safety Analys is Report. 


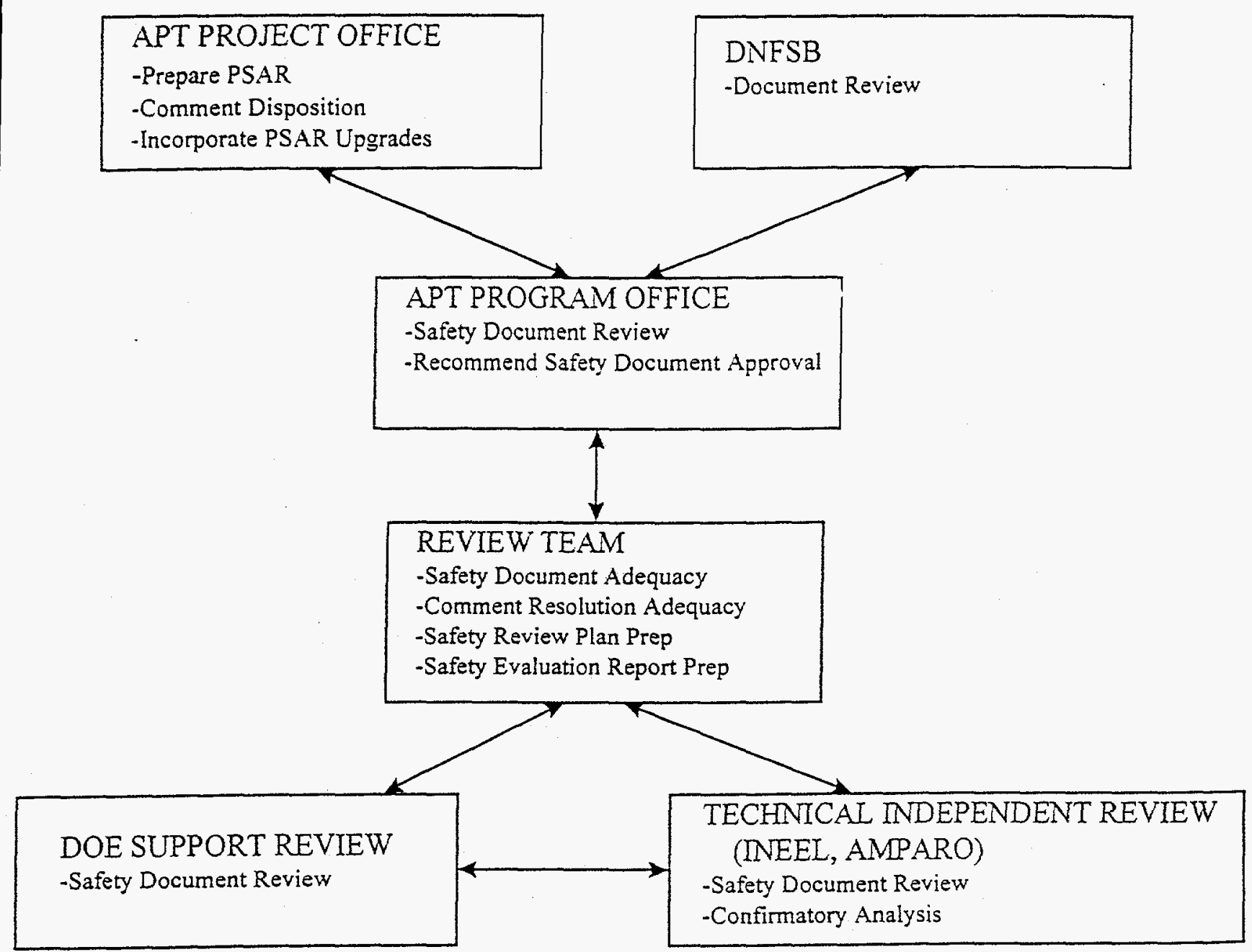

Figure 3-1. Independent Safety Review Interfaces 
6. The APT plant will be classified Hazard Category 2 and meet the corresponding safety requirements as defined by DOE-STD-1027, Hazard Categorization and Accident Analysis Techniques, for compliance with DOE Order 5480.23 .

7. The accelerator portion of the APT plant will meet the safety requirements of DOE Order 5480.25, Safety of Accelerator Facilities through implementation of the parallel requirements in DOE order 5480.23 .

8. APT facilities will be designed with the objective of providing defense in depth, such that layers of defense against release of hazardous materials are provided.

9. SSCS will be designed to reliably perform their safety function under those conditions and events for which their safety function is intended.

10. SSCs will be designed to withstand design basis loading associated with providing their safety functions with an appropriate margin of safety.

11. The single-point failure criterion, requirements, and design analys is identified in ANSI/IEEE 279 will be applied during the design process as the primary method of ensuring SSCs perform all safety-class functions with the reliability indicated by the safety analysis.

12. Environmental qualification will be used to ensure that safetyclass SSCs can perform required safety functions, as determined by the safety analysis with no failure mechanism that could lead to common cause failures under postulated service conditions.

13. The plant design will provide reliable safe shutdown conditions and sufficient confinement of hazardous materials during and after all DBAs.

14. Normally occupied space containing a nitrogen or helium system will be provided with an oxygen deficiency monitor, if a failure of any line in the space could release a flowrate of nitrogen or helium large enough to cause the percentage of oxygen in the space to fall below 
$19.5 \%$.

15. Safety systems will be designed to fail-safe on loss of power or motive force.

16. Liquid systems near safety equipment will be designed such that a release of liquid would preclude the operation of safety equipment.

17. As Low As Reasonable Achievable (ALARA) principles will be applied for both radiological and non-radiological toxic hazards to limit exposure to workers, the public and the environment.

18. OSHA regulations will be followed to ensure protection of workers not specifically protected by a safety-significant function.

19. Requirements resulting from the emergency response analys is will be met. Asbestos or asbestos-containing materials will not be used.

20. Facilities will be designed such that the stored energy sources (electrical, pressure vessels, or chemical) are controlled during normal conditions, anticipated operational occurrences, off-normal conditions, and maintenance so as to minimize the threat to radiological and hazardous material barriers and to protect workers.

21. Backup power equipment areas will be ventilated to exhaust hazardous gases (if applicable) and to maintain satisfactory ambient temperatures for equipment operation or personnel access.

Radiological

22. Facilities and equipment must be designed and operated to minimize doses to ALARA.

23. Primary methods to maintain radiation exposure ALARA will be physical design features. Administrative controls and procedural requirements will be employed only as supplemental methods to control radiation exposure. 
24. Access to any areas in which an individual could receive a "deep dose" equivalent in excess of $5 \mathrm{mrem} / \mathrm{hr}$ will be controlled, as specified in 10 CFR 835.603 (a).

25. Area and air radiation monitoring systems will be supplied to provide workers timely warning of abnormal radiation or airborne contamination levels.

26. The plant will contain designated areas for radiological support functions: personnel and instrumentation decontamination, instrument and records storage, and personnel office space.

27. Plant layout will be based on segregation of plant functional areas. The basis for segregation will be contamination control, shielding and accessibility. The first level of segregation should be to separate process areas from non-process areas.

28. The design of confinement and ventilation systems to limit airborne contamination concentrations will ensure that respiratory protection is not relied upon during normal operation.

29. The plant will be provided with an effective confinement system to prevent migration of radioactive and hazardous materials from confinement enclosures, containment vessels, and process equipment for unoccupied and occupied areas.

30. Plant design will minimize release of radicactive and other hazardous materials in $\mathrm{plant}$ effluents during all normal and anticipated abnormal events.

31. The design will provide for monitoring of occupational workers in work areas where radioactive materials are stored and handled.

32. Radiation monitoring system signals (continuous air monitors, alarms associated with stack monitoring systems) will have read-out and alarm panels at a centralized location and a local station alarm panel that are accessible as required by safety analysis.

33. Straight-line penetrations of shield walls will be avoided to prevent radiation streaming. 
34. Plant design will incorporate features that will facilitate decontamination.

35. Spill prevention and control will be considered in design of the plant to minimize the possibility of accidental release of hazardous materials and waste to the environment.

36. Plant design will incorporate cradle-to-grave radiological process sampling and handling techniques.

\section{Technical Approach to the PSAR Review}

The reviews described in this SRP pursue the philosophy and principles discussed in:

DOE-STD-3009-94 for Hazard Category 2 (Target/blanket, Tritium Separation System) and Hazard Category 3 (Linear Accelerator, Balance of Plant) structures, systems, and components;

Savannah River Site implementing guidelines; and

APT Safety Implementation Plan (draft), June 16, 1997; and

as further specified in DOE-STD-1104-96.

It is anticipated that information and data provided in each PSAR chapter/section will describe the as designed APT feature (environment, SSC, program, process, human action) in sufficient detail (including referencing other APT system documentation) to clearly identify them in the hazard and accident analys is reported in Chapter 3 of the PSAR. Or, it is anticipated that information and data provided in each chapter/section of the PSAR will clearly demonstrate that the subject feature is not an issue for the hazard and accident analysis. For example, if there are no human actions required for the operation of the target/blanket a safety demonstration is not an appropriate subject of the PSAR.

The reviews will also take into consideration the fact that the APT reported in the PSAR is an as designed rather than an as built facility. As such, judgements regarding the safety relevance of environmental, SSC, program, process, and human action features will rely on the information of 
the type anticipated above. In cases where a judgement cannot be made based on the information and data provided, a determination will be made that the associated chapter/section of the PSAR is not acceptable.

In summary, the APT ISRC will focus exclusively on radiological, chemical, and industrial safety. Its reviews will consider anomalies as may occur during APT start-up, normal operation, excursions (off-normal, unusual, emergency, accident events), shut-down and on-line and outage maintenance. Reviews will be in accordance with requirements and criteria established in pertinent DOE orders and standards, and in DOE approved implementing guidelines prepared by the Savannah River Site which will host the APT Facility. Non-safety related issues (e.g., mission, investment, cost-benefit ratio, operating efficiency) will not be a focus of the ISRC reviews. The concepts of safety class and safety significant as described in DOE-STD-300994, will be involved as appropriate based on the geographical location of the APT facility juxtaposed with other facilities and roadways on or near the Savannah River Site.

The ISRC will assess each APT environmental, structural, process, and programmatic as designed feature for its propensity as an initiator and mediator of safety and risk. Each as designed feature will be reviewed for its safety significance/insignificance based on its consideration in the hazard and, if appropriate, the accident analysis. It will be expected that each major as designed feature reported in the PSAR will be accompanied by interpretable evidence of its (1) inclusion in these analyses, and (2) its relevance to safety and risk. See Section 6.4 for criteria that will be used to review the PSAR, on a chapter-by-chapter basis.

\section{PSAR Reviews and Assignments}

\subsection{Review Team Organization}

The independent review team is composed of DOE and INEEL contractor support personnel with the required expertise to identify any safety issues in the PSAR associated with the APT facility and operation. The overall participation in the review by the two organizations is shown in Table 6-1. The leads for consolidating the comments for each of the chapters are also provided in the Table. 
Table 6-1

\begin{tabular}{|c|c|c|c|}
\hline PSAR Chapter & DOE DP-45 & INEEL/AMPARO & Lead \\
\hline Exec Summary & Dae Chung & $\begin{array}{l}\text { All } \\
\text { Tom Ward }\end{array}$ & Review Team \\
\hline $\begin{array}{l}\text { 1. Site } \\
\text { Characteristics }\end{array}$ & $\begin{array}{l}\text { Jeff Kimball - } \\
\text { seismologist }\end{array}$ & K. Moor & Dae Chung-DOE \\
\hline $\begin{array}{l}\text { 2. Facility } \\
\text { Description }\end{array}$ & $\begin{array}{l}\text { Rick Kendall -I\&C } \\
\text { Bill Froh -Fire } \\
\text { Protection } \\
\text { Dae Chung - } \\
\text { Neutronics }\end{array}$ & $\begin{array}{l}\text { G. Dinneen } \\
\text { T. Ryan } \\
\text { J. Edson } \\
\text { J. Hansen }\end{array}$ & $\begin{array}{l}\text { Gerald Dinneen- } \\
\text { INEEL }\end{array}$ \\
\hline $\begin{array}{l}\text { 3. Hazard and } \\
\text { Accident Analysis }\end{array}$ & $\begin{array}{l}\text { Bill Froh -FP } \\
\text { Dae Chung - } \\
\text { Neutron } \\
\text { Kamiar Jamali - } \\
\text { PRA } \\
\text { Rick Kendall - I\&C }\end{array}$ & $\begin{array}{l}\text { G. Dinneen } \\
\text { T. Ryan } \\
\text { Geo. Beitel } \\
\text { J. Jones }\end{array}$ & Dae Chung-DOE \\
\hline $\begin{array}{l}\text { 4. Safety } \\
\text { Structures, } \\
\text { Systems, and Comp }\end{array}$ & $\begin{array}{l}\text { Bill Froh -FP } \\
\text { Dae Chung - } \\
\text { Neutronics } \\
\text { Kamiar Jamali - } \\
\text { PRA } \\
\text { Rick Kendall -I\&C }\end{array}$ & $\begin{array}{l}\text { G. Dinneen } \\
\text { T. Ryan } \\
\text { N. Morcos } \\
\text { C. Fineman } \\
\text { J. Jones }\end{array}$ & $\begin{array}{l}\text { Nabil Morcos- } \\
\text { INEEL }\end{array}$ \\
\hline 5. Deriv of TSR & & $\begin{array}{l}\text { G. Dinneen } \\
\text { N. Jensen }\end{array}$ & $\begin{array}{l}\text { Nels Jensen- } \\
\text { INEEL }\end{array}$ \\
\hline $\begin{array}{l}\text { 6. Inadvertent } \\
\text { Critical }\end{array}$ & $\begin{array}{l}\text { Dae Chung - } \\
\text { Neutronics }\end{array}$ & $\begin{array}{l}\text { L. Montierth } \\
\text { N. Morcos } \\
\text { Tom Ward }\end{array}$ & $\begin{array}{l}\text { Nabil Morcos- } \\
\text { INEEL }\end{array}$ \\
\hline 7. Rad Protect & & $\begin{array}{l}\text { N. Rohrig } \\
\text { H. Peterson } \\
\text { Tom Ward }\end{array}$ & $\begin{array}{l}\text { Henry Peterson- } \\
\text { INEEL }\end{array}$ \\
\hline
\end{tabular}




\begin{tabular}{|c|c|c|c|}
\hline PSAR Chapter & DOE DP-45 & INEEL/AMPARO & Lead \\
\hline $\begin{array}{l}\text { 8. Haz Material } \\
\text { Protection }\end{array}$ & & $\begin{array}{l}\text { C. O'Donne11 } \\
\text { AMPARO }\end{array}$ & $\begin{array}{l}\text { Charles } \\
\text { 0'Donnel1-INEEL }\end{array}$ \\
\hline $\begin{array}{l}\text { 9. Rad and Haz } \\
\text { Waste Management }\end{array}$ & & $\begin{array}{l}\text { R. Pederson } \\
\text { H. Peterson } \\
\text { AMPARO }\end{array}$ & $\begin{array}{l}\text { Robert Pederson- } \\
\text { INEEL }\end{array}$ \\
\hline $\begin{array}{l}\text { 10. Test, Surv } \\
\text { and Maint. }\end{array}$ & & $\begin{array}{l}\text { J. Hansen } \\
\text { N. Jensen } \\
\text { AMPARO }\end{array}$ & $\begin{array}{l}\text { Jeff Hansen- } \\
\text { INEEL }\end{array}$ \\
\hline $\begin{array}{l}\text { 11. Operational } \\
\text { Safety }\end{array}$ & Bill Froh -FP & N. Jensen & $\begin{array}{l}\text { Nels Jensen- } \\
\text { INEEL }\end{array}$ \\
\hline $\begin{array}{l}\text { 12. Procedures } \\
\text { and Training }\end{array}$ & & N. Jensen & $\begin{array}{l}\text { Nels Jensen- } \\
\text { INEEL }\end{array}$ \\
\hline 13. Human Factors & Frank Rowsome - HF & T. Ryan & Tom Ryan-INEEL \\
\hline $\begin{array}{l}\text { 14. Quality } \\
\text { Assurance }\end{array}$ & & K. Sowder & Ken Sowder-INEEL \\
\hline $\begin{array}{l}\text { 15. Emergency } \\
\text { Preparedness }\end{array}$ & & $\begin{array}{l}\text { S. Schum } \\
\text { R. McCarde11 }\end{array}$ & $\begin{array}{l}\text { Scott Schum- } \\
\text { INEEL }\end{array}$ \\
\hline $\begin{array}{l}\text { 16. Decon and } \\
\text { Decommissioning }\end{array}$ & & K. Moor & Ken Moor-INEEL \\
\hline $\begin{array}{l}\text { 17. Management } \\
\text { and Organization }\end{array}$ & & T. Ryan & Tom Ryan-INEEL \\
\hline $\begin{array}{l}\text { 1-17. Statues, } \\
\text { rules and Orders }\end{array}$ & & J. Close & $\begin{array}{l}\text { James Close- } \\
\text { INEEL }\end{array}$ \\
\hline $\begin{array}{l}\text { 1-17. Health and } \\
\text { Safety Crit }\end{array}$ & & $\begin{array}{l}\text { C. O'Donnell } \\
\text { H. Peterson }\end{array}$ & $\begin{array}{l}\text { Charles } \\
\text { 0'Donne11-INEEL }\end{array}$ \\
\hline $\begin{array}{l}\text { 1-17. Design } \\
\text { Codes and } \\
\text { Standards }\end{array}$ & & $\begin{array}{l}\text { V. Gorman } \\
\text { J. Close }\end{array}$ & $\begin{array}{l}\text { Vince Gorman- } \\
\text { INEEL }\end{array}$ \\
\hline
\end{tabular}

Whether the lead for a given chapter is associated with DOE or INEEL, review and comment contributions from both organizations are to be 
incorporated into the overall independent review process.

The DOE review is under the direction of Dae Chung DP-45. The reviewers performing this review are from other organizations within DOE. The selection of the review members is based on their review expertise. All of the DOE review members has been screened to determine that they do not have ties to the APT so that they can participate in the review as being independent.

The review of the APT PSAR will be a joint effort between the INEEL review team members including AMPARO, a consultant for reviewing the accelerator safety aspects and DOE.

The LMITCO organization that supports the independent raview of the Accelerator Production of Tritium (APT) is shown on the Figure 6-1. As can be seen from the organizational structure, the inanagement support is tied directly to the president of the company for the Principal Investigator for the APT and the necessary personnel are available for assistance on the review of the safety analysis reports associated with the APT.

The LMITCO review will follow a two tier approach for performing the APT review task using a core team approach under the direction of Gerald Dinneen. Mr Dinneen is assigned the task of Principal Investigator to accomplish the overall task. The LMITCO core team will consist of three members for performing the lead function in the following areas for the review of the APT: Gerald Dinneen - Accident Analysis; Thomas Ryan - Safety Management Program; and Kenneth Moor - Site Characteristics and Cleanup. It is the responsibility of each of the core team members to coordinate and consolidate the comments on the PSAR chapters assigned to the member and identify any outstanding issues. The core team's responsibility is to ensure that the comments on the PSAR are consistent among the chapters, a consistent categorization of the comments has been made, and all of the comments are valid. All of the individual review functions of the APT safety documents will be included in the above mentioned functions.

AMPARO will support the INEEL staff in the review of the safety of accelerators as well as the neutronic associated with the target/blanket and nuclear data issues. 


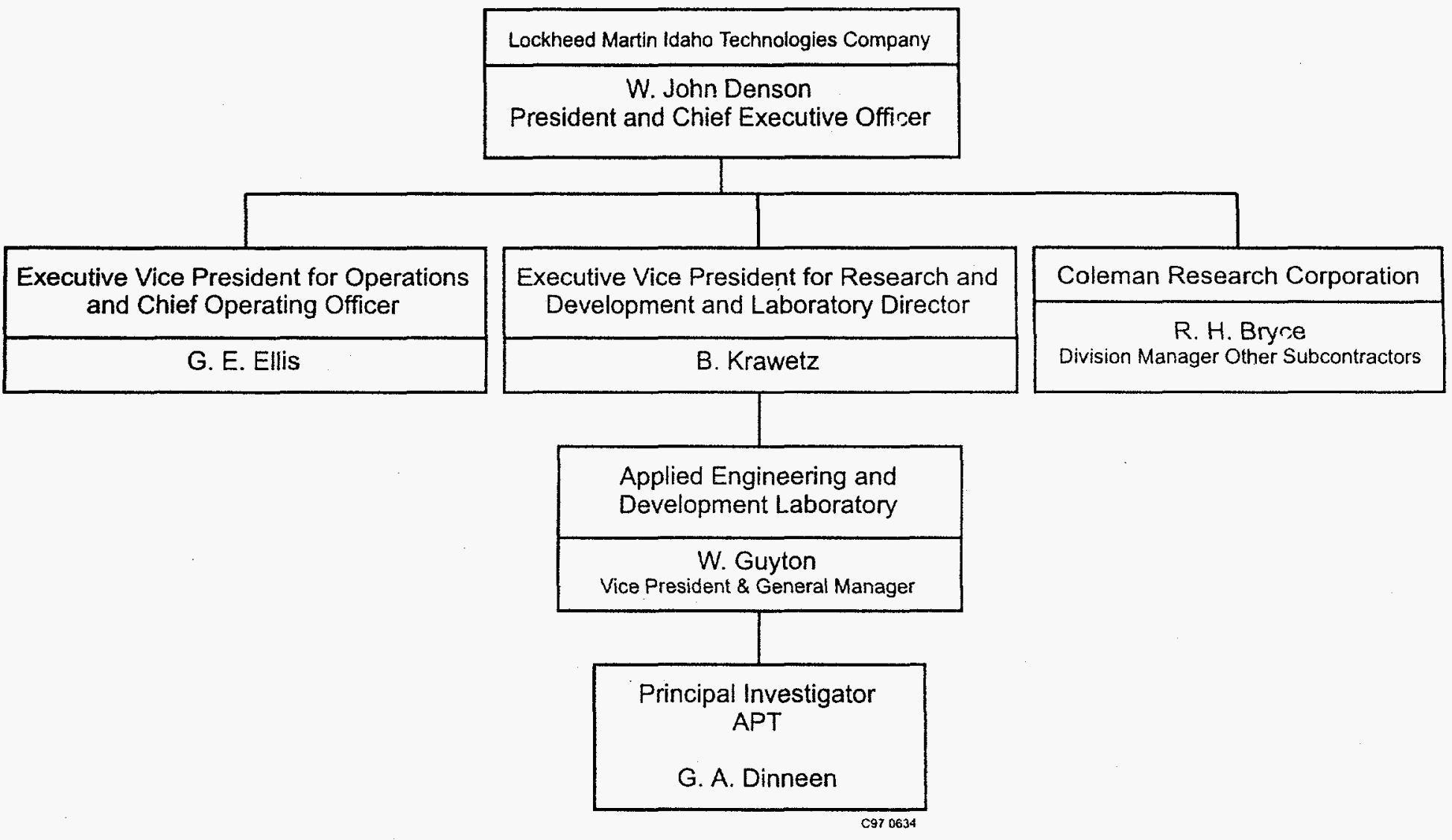

Figure 6-1 Lockheed Management Structure 


\subsection{Documentation of Comments}

\subsubsection{Levels of Comments}

Comments provided by the ISRC on sections and sub-sections of each chapter of the APT PSAR will be in a standard format. Three levels of comments will be provided to the PSAR preparers.

The highest level of comment will be "Significant". Significant comments will directed toward discrepancies from one or more of the safety-related criteria established for the review (DOE-STD-3009-94, Savannah River Site implementing guidelines, and APT Safety Implementation P1an). Section 6.4 presents these criteria on a chapter-by-chapter basis. Significant comments will require a formal response and action statement from the PSAR preparers. Significant comments will be tracked to resolution and will become part of the technical basis for the SER.

The next highest level of comment will be "Optional". Optional comments will be directed toward discrepancies from one or more of the format and content criteria established for the review (DOE-STD-3009-94, Savannah River Site implementing guidelines, and APT Safety Implementation Plan). Optional comments will not require a formal response and action statement from the PSAR preparers. Optional comments will only be tracked by the ISRC if they are to become notations in the SER.

The lowest level of comment will be "Editorial". Editorial comments will be directed toward discrepancies in spelling, mislabeling, sentence structure, etc. Editorial comments will not require a formal response and action statement from the PSAR preparers. Editorial comments will not be tracked by the ISRC.

\subsubsection{Format and Content of Comments}

Figure 6-2 presents the comment form that will be used for a11 APT PSAR and related documentation reviews. The form is divided into 10 entry boxes. 
Figure 6-2 Comment/Resolution Form

\begin{tabular}{|c|l|l|}
\hline $\begin{array}{c}\text { REVIEW COMMENT RECORD (RCR) } \\
\text { (Safety Document Title) } \\
\text { (Document Number) } \\
\text { (rev and date) }\end{array}$ & $\begin{array}{c}\text { 1. Date } \\
\text { (date of review) }\end{array}$ & 3. Review No. \\
\cline { 2 - 4 } & 2. Project No. & 4. Page \\
\hline
\end{tabular}

\begin{tabular}{|c|c|c|c|c|c|}
\hline 5. I tem & $\begin{array}{l}\text { 6. Comment(s)/Discrepancy(s) (Provide } \\
\text { technical justification for the comment.) }\end{array}$ & $\begin{array}{l}\text { 7. Recommendation (Provide detailed } \\
\text { recormendation of the action required to } \\
\text { correct/resolve the discrepancy/problem } \\
\text { indicated.) }\end{array}$ & $\begin{array}{l}8 . \\
\text { Hold } \\
\text { Point }\end{array}$ & $\begin{array}{l}\text { 9. Disposition (Provide justification if } \\
\text { NOT required.) }\end{array}$ & $\begin{array}{l}10 . \\
\text { Status }\end{array}$ \\
\hline $\begin{array}{c}\text { din-1 } \\
\text { chap } \\
\text { page } \\
S\end{array}$ & & & & & \\
\hline & & & & & \\
\hline & & & & & \\
\hline & & & & & \\
\hline & & & & & \\
\hline & & & & & \\
\hline & 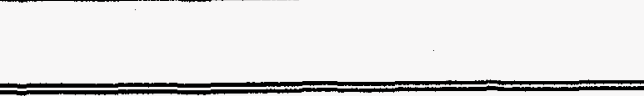 & 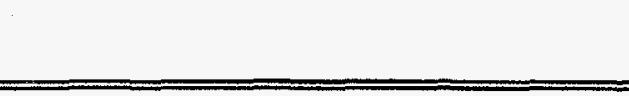 & & & \\
\hline
\end{tabular}

Comment Coding

S significant,

O Optional, 
Box 1 will contain the date of the review. This date will change for each iteration between the PSAR preparers and the ISRC.

Box 2 will contain the project number assigned to the PSAR review.

Box 3 will contain the phase of the review that is being performed. The first phase is the review comment generation, the second phase is the comment resolution by the Project office, the third phase is the review of the resolution by the independent reviewers, and the fourth phase is the buy-off by of any changes needed for the resolutions from the Project office.

Box 4 will contain the sequential page number for comments on the Project No. as described in Box 2.

Box 5 will contain the reviewer's unique identifier (e.g., din), PSAR chapter number, page number, and paragraph number of each comment presented in Box 6 . Box 5 will also contain the classification of each comment as Significant (S), Optional (O), or Editorial (E).

Box 6 will contain a narrative statement of each comment. Each narrative will be tied to one or more of the criteria established for the review (DOE-STD-3009-94, Savannah River Site implementing guidelines, APT Safety Implementation Plan).

Box 7 will contain one or more options or recommendations for responding, and resolving the comment. Box 7 will be completed only for comments classified by the mid-level and working-level reviewers as Significant or Optional. Box 7 will be completed by the mid-level and working-level reviewers for Optional comments since they may be subsequently judged Significant by the Top-Level Review Team.

Box 8 will be used by only the Top-Level Review Team to indicate the hold point for each comment, that is, comments considered for reclassification, being held for further information from the reviews, or comments forwarded to the PSAR preparers for action. Box 8 entries may change with each iteration of a given comment.

Box 9 will be completed by the PSAR preparer in response to each Significant comment forwarded by the Top-Level Review Team. Upon 
receipt of each response from the PSAR preparers, the Top-Level Review Team will either accept or reject the response itself, or will forward the response to the mid-level and working-level reviewers for determination of acceptance or rejection. The disposition of the response in any case will be reflected in Box 8 . Each comment will go through two cycles of acceptance. The first will be an acceptance on the basis of the response offered in Box 9. The second acceptance will be on the basis of the manner in which the response is implemented in the PSAR.

Box 10 will be used only by the Top-Level Review Team to indicate notation status of each Significant (in special cases Optional) comment being tracked. Notations of "Response Open" will indicate a response is pending, and a "Response Closed" notation will indicate a response has been accepted for implementation. Similarly a "Implementation Open" notation will indicate a PSAR revision is pending, and "Implementation closed" notation will indicate a PSAR implementation that has been accepted.

The comment/resolution form will become a record when the review team signs and dates the comment/resolution form indicating that the comments are adequately resolved. However, configuration management will be maintained for the comment/resolution form during the process of generating the comments, the disposition of the comment by the Project office, and the technical acceptance of the dispositions by the Independent Review Team.

\subsection{Review Criteria}

The Independent Safety Review of the APT PSAR will follow the review process indicated by the flow diagram as shown in Attachment 1 . As indicated in the flow diagram, some of the steps in the review process need to be screened using acceptance criteria prior to proceeding to the next box. The review flow process is described as follows, as indicated by the Box numbers on the flow diagram.

Box 2 - The document to be reviewed will be provided by the Project office to the Review Team. The Review Team will perform a global review of the document to meet the following criteria. The criteria to be used by the review team in accepting the initial PSAR for 
review would include: a) does the SAR meet the format of DOE STD-3009, b) is there sufficient information contained in the document to perform a safety review, c) does the document meet the Safety Implementation Plan criteria, d) is the document sufficiently reviewed by the preparers prior to transmittal, e) are the relevant supporting documentation available for the review team, $f$ ) is a reference list provided of the references needed to perform a safety review, g) is the scheduling of the PSAR chapter submittals consistent with the independent review process. If the document is deficient, it will be returned to the Project office for corrections. If the document is satisfactory, it will be sent to the Independent Reviewers for technical review.

Box 3 - The Independent Reviewers will use the criteria in this Safety Review Plan to evaluate the adequacy of the document. The criteria to be used by the independent review team for accepting the initial PSAR for review would include: a) does it meet the format of DOE STD-3009 and associated SRS implementation documents, b) are the necessary supporting documents available for our review, c) are the General Headings in the Chapters consistent with the APT design, and d) does the document implement the DOE requirements associated with DOE Orders 5480.25, 5480.23, and 420.1. Any discrepancies resulting from the review will be documented on the comment review form. The resulting comments will be reviewed by the INEEL Independent Review Core Team to confirm the validity of the comments and ensure that the comment classification is valid. The comments will then be forwarded to the Review Team for consolidation of both the INEEL and DOE comments.

Box 7 - The Review Team will assess the consistency of the comment classification and validity of the comments. The validation of comments from the reviewers by the Review Team for the PSAR would include: a) review the comment categorization for consistency, and b) recategorize the comment after discussing with the reviewers. Only the "Significant" comments will require a disposition of the comment. The "editorial" and "optional" comment will be provided to the PSAR preparer for their information. The Review Team will forward the comments to the Project office for the resolution by the PSAR preparers.

Box 8 - The PSAR comments will be reviewed and a resolution will be incorporated on the comment review form. This resolution will identify the proposed changes to the PSAR in the comment resolution. 
After a peer review, the comment resolutions will be forwarded to the APT Project Office for transmittal to the Review Team.

Box 9 - The Review Team will review the comment resolutions for overall adequacy and completeness. The Review Team acceptance criteria for the review of the resolution of comments would use similar criteria as identified in Box 2 to determine the acceptability of the responses to the PSAR. If the comment resolution are acceptable, they will be forwarded to the Independent Review for a review of the technical adequacy of the resolutions.

Box 10 - The Independent Reviewers will perform a review to ensure that the resolutions adequately address the original comments. The independent review of the comment responses and purposed revised sections of the PSAR would use the same criteria as used in Box 3 to determine the acceptability of the responses and revised sections. Any outstanding issues will be identified for inclusion in the SER. A draft of the initial version of the SER will be initiated by the Independent Reviewers. The results of the Independent Reviewers will be forwarded to the Review Team for final acceptance of the comment resolutions.

Box 12 - The Review Team will screen the results of the comment resolution review and identify issues that are unacceptable and must still be addressed by the APT Project office. The criteria used for the validation of comment responses by the Review Team is similar to process noted in Box 7. These issues will be forwarded to the Project Office for resolution. Those issues that are acceptable will be categorized and forwarded to the Project office for final buy-off of the resolutions.

Box 13 - The Project Office will forward the approved comment responses to PSAR preparers for the updating any changes from these responses into the PSAR. Upon completion of the PSAR update, the PSAR will be forwarded to the Review Team for final review.

Box 15 - The Review Team will perform a global review to ensure the comment resolutions are incorporated satisfactorily and that the PSAR is complete in following the requirements of DOE STD-3009-94. The specific review criteria for the Review Team's review of the updated PSAR would use criteria similar to that identified in Boxes 2 and 9. 
Once the PSAR has been accepted by the Review Team, the revised PSAR would be provided to the DNFSB for their review and to the Independent Reviewers for their acceptance review.

Box 16 - The Independent Reviewers will assess the technical adequacy of the PSAR for incorporating the comment resolutions. The acceptance or rejection of the updated PSAR would be based on acceptance criteria similar to that used in Boxes 3 and 10 . The findings of this review will be given to the Review Team for the resolution of any outstanding issues.

Box 17 - The review team will identify any outstanding issues and forward them to the Project office for disposition. The review of issues identified during the review of the revised PSAR by the Review Team would use criteria similar to that contained in Boxes 7 and 12 . If the updated PSAR is acceptable it will be forwarded to the APT Program office.

Box 18 - The APT Program Office will make the final approval of the updated PSAR.

Box 24 - The Review Team will prepare the draft SER based upon the input from the Independent Reviewers prepared during their review and the resolution of issues from the APT Program Office. Once the draft SER is prepared, it is to be reviewed by a review panel consisting of DP-20, and SRS.

Box 26 - Following the draft SER review the comments are provided to the APT Program Office. Any comments from the DNFSB related to the SER will be given to the Program office at this time. Following the decision on what changes to the SER are required by the Program office, the draft SER will be given to the Review Team for incorporation in the final SER. Approval of the SER is the responsibility of the APT Program Office.

Box 27 - The Review Team will incorporate changes into the SER and issue the Final SER upon approval of the APT Program Office.

Box 28 - Once the final changes to the PSAR are made, the approval to issue the PSAR will be given by the APT Program Office to 
the APT Project office to issue the PSAR.

\subsection{PSAR Review Criteria}

The following criteria are to be used during the independent review of the PSAR to assess the minimum DOE requirements are met. In addition, any federal, state, and health requirements are identified. This section provides the requirements in three different parts: those requirements from the PSAR chapters primarily involved with the accident analysis, chapters $3,4,5$ and 6 ; those requirements from the PSAR chapters involved with the site characteristics and cleanup, chapters 1,2, and 16; and those requirements from the PSAR chapters involving the programmatic issues, chapters 7 through 15 , and 17 .

\subsubsection{Accident Analys is}

The APT ISRC considers Chapters 3 through 6 to be the accident analysis chapters for purposes of the APT PSAR review, and preparation of the SER. The topic and sub-topics of each of these chapters represent the APT's implementation by design, therefore, each has the potential of affecting safety in an adverse manner. Given the ISRC's interest in safety over mission, efficiency, and cost, the following chapter-by-chapter criteria will be used to verify that each topic and sub-topic representing an as-designed feature of the APT is "safe." It is considered the responsibility of the PSAR preparer to demonstrate that the design basis for each topic and sub-topic achieves a safe operating environment.

Each set of criteria is based on guidelines set forth in DOE-STD-3009-94 as further refined by Savannah River Site guidelines and criteria (as approved) and the APT Safety Implementation Plan (as approved).

\section{Chapter 3 Hazards and Accident Analysis}

\section{DOE-STD-3009-94, Pages 31-59}

Does the chapter provide a summary of the hazards analys is associated with the facility and its proposed operations? The appropriateness of the overall methods used to evaluate hazards 
must be presented and justified. This justification focuses on the selection of a technique for the given process selected.

Does the chapter provide the results of the hazard identification activity, either by direct inclusion of or by reference to the hazards identification data sheets?

Does the chapter provide the identification of hazardous material and energy sources present by type, quantity, form and location?

Does the chapter provide the final hazard classification activity in accordance with DOE STD-1027-92?

Does the chapter provide the hazards evaluation presents potential accidents in terms of hazards, energy sources, preventive and mitigative features, consequence estimates, and frequency estimates? Where a large number of scenarios are involved, present simple summaries in the text of this chapter with detailed tables generated in the performance of the hazard evaluation included as an appendix to the SAR.

Does the SAR present a summary of the significant aspects of the defense in depth, and identifies associated safety-significant SSCs and other items needing TSR coverage? This includes both facility design and administrative features.

Does the chapter distinguish the safety-significant SSCs from among the structures, systems, and components contributing to defense in depth?

Does the chapter present a summary of those safety-significant SSCS and other aspects of defense in depth that require TSR coverage in accordance with the screening criteria of DOE 5480.22?

Does the chapter provide the specific features protecting the workers from the hazards of facility operation? Summary products germane to worker safety include:

- General overview of worker safety in terms of SSCs and administrative features. 
- Identification of any safety-significant SSCs.

- Identification of any safety management programs that will

be assigned TSR coverage in the form of administrative controls for adequate worker safety.

Does the chapter document the pathways for uncontrolled release of large amounts of hazardous material to the environment as identified in the hazard evaluation?

Does the chapter provide Numerical Evaluation Guidelines and legal limits on normal operation inherently place an upper bound on potential environmental release? Further, issues of environmental contamination are not directly safety protection issues. Safety SSC designations are not required for issues solely related to environmental protection.

Does the chapter identify the Design Basis Accidents (DBAs) results from the hazards evaluation ranking of the complete spectrum of facility accidents that satisfies the requirements of DOE 5480.23 for "a complete set of bounding conditions"? The rationale for the binning of the accidents into frequency of occurrence shall be provided.

Does the chapter document the development of the source term estimate and the consequence results for the accident analysis?

Does the results of the accident analysis in the chapter identify the requirement for any safety-class SSCs and TSRs needed for protection of the public?

Does the chapter identify all of the major assumptions in the accident analysis?

Does the chapter include all of the categories of DBAs that include:

- Operational accidents (caused by initiators internal to the facility.

- Natural phenomena events (e.g., earthquake, tornadoes).

- External events (caused by man-made initiators external to 
the facility.

All assumptions made in the accident analysis are to be validated as part of the accident analysis activity.

Does the chapter identify and describe any computer programs used to implement accident analysis? This includes a description of the origin of the code, its precedent for use, input data, range of variables investigated, the basic analytical models, their interrelationships, and the progression of the analysis.

Does the chapter provide a comparison of the accident analysis results for the accident sequences to Evaluation Guidelines? If the Evaluation Guidelines cannot be met, provide a summary assessment of the significance of the failure to meet Evaluation Guidelines and administrative and/or engineered controls whose implementation would allow the guidelines to be met.

Does the chapter identify the safety-class SSCs and assumptions judged to require TSR coverage to meet Evaluation Guidelines as a results of the accident analysis?

Does the chapter satisfy the DOE 5480.23 requirement for evaluating accidents beyond the design basis so that a perspective of the residual risk associated with the operation of the facility can be made? Such beyond DBAs are not required to provide assurance of the public health and safety. These accidents serve as a bases for evaluating the cost-benefit considerations if consequences exceed the Evaluation Guidelines.

\section{Savannah River Site (as approved) Implementing Guideline/Criteria}

Does the accident analysis evaluation guidelines meet the criteria established in Functional Classification Methodology Manual, WSRCTM-93-9, Rev 3?

Does the hazard assessment for identifying "Safety Significant" functions include the 3 receptor locations? 1) the site worker in the immediate area of the hazard, 2) the site workers within the room or building associated with the hazard, 3) the site worker 
that is outside the last possible physical means of containing the hazard. (WSRC-TM-93-9, p-34)

Does the hazards analysis conform to the methodology requirements specified in Hazards Analysis Methodology Manual (U) WSRC-IM-97-9?

\section{APT (as approved) Safety Implementation Plan (Section 3.)}

Does the chapter identify that the SSCS have been evaluated for natural phenomena hazards in accordance with the performance categories from DOE STD-1020 and 1021?

Does the chapter identify that the requirements established in DOE STD-3009-94 are met?

\section{Chapter 4 Safety Structures, Systems, and Components}

\section{DOE-STD-3009-94. Pages 60-68}

Does the chapter provide a description of the SSCs, including safety functions?

Does the chapter provide the identification of support systems that the safety SSCS are dependent upon to carry out safety functions?

Does the chapter provide the identification of the functional requirements necessary for the safety SSCs to preform their safety functions, and the general conditions caused by postulated accidents under which the safety SSCs must operate?

Does the chapter provide the identification of the performance criteria necessary to provide reasonable assurance that the functional requirements will be met?

Does the chapter provide the identification of assumptions needing TSR coverage? 
Does the chapter identify the design codes, standards, regulations and DOE Orders which are required for establishing the safety basis of the facility?

Does the chapter provide a summary list of safety-class SSCs? This summary should provide the accident requiring the safetyclass, the safety functions to be performed, the functional requirements to be accomplished, and the performance criteria judged to require TSR designation coverage.

Does the chapter provide the details associated with the identification of safety-class SSCs, the specific identification of its preventative or mitigative safety functions from the hazard and accident analysis, the system description including failures that could result in loss of safety function, the specific functional requirements needed to fulfill the required safety function, the performance criteria imposed on the safety class SSC so that it can meet the functional requirements that thereby satisfy its safety function, and the identification of those assumptions requiring TSRs to ensure performance of the safety function?

Does the chapter provide a summary list of safety-significant SSCs? This summary should provide the accident requiring the safety-significant, the safety functions to be performed, the functional requirements to be accomplished, and the performance criteria judged to require TSR designation coverage.

Does the chapter provide the details associated with the identification of safety-significant SSCs, the specific identification of its preventative or mitigative safety functions from the hazard and accident analysis, the system description including failures that could result in loss of safety function, the specific functional requirements needed to fulfill the required safety function, the performance criteria imposed on the safety significant SSC so that it can meet the functional requirements that thereby satisfy its safety function, and the identification of those assumptions requiring TSRs to ensure performance of the safety function? 


\section{Savannah River Site (as approved) Implementing Guideline/Criteria}

Does the selection of Safety Significant and Safety Class functional requirements follow the requirements of SRS Procedural Manual E-7, Conduct of Engineering and Technical Support (U)?

\section{APT (as approved) Safety Implementation Plan (Safety Design Requirements - Attachment 3)}

Does the chapter identify and evaluate the conformance to the codes and standards necessary to perform the safety function of the SSCs?

Does the chapter describe and evaluate the appropriate protection of SSCs against the dynamic events such as the effect of internally generated missiles?

Does the chapter identify the fire detection and protection systems that would minimize the adverse effects of fires on SSCS important to safety? Also, the chapter should demonstrate that the inadvertent operation of the fire-fighting systems does not significantly impair the safety capabilities of these SSCs.

Does the chapter identify the onsite and offsite electric power system that permit functioning of the SSCS assuming one of the power systems is not functioning.

\section{Chapter 5 Derivation of Technical Safety Requirements}

\section{DOE-STD-3009-94. Pages 69-73}

Does the chapter provide information with sufficient basis from which to derive, as appropriate, any of the following TSR parameters for individual TSRs:

- $\quad$ Safety Limits (SLs)

- Limiting Control Settings (LCSs)

- Limiting Conditions for Operation (LCOS)

- Surveillance Requirements 
Does the chapter provide information with sufficient basis from which to derive TSR administrative controls for specific control features or to specify programs necessary to perform institutional safety functions?

Does the chapter identify the passive design features addressed in the SAR?

Does the chapter identify TSRs from other facilities that affect the facility's safety basis?

Does the chapter provide a listing of the design codes, standards, regulations and DOE Orders which are required for establishing the safety basis of the facility.

Does the chapter provide a summary of the TSRs that identifies the relevant hazard and the major features relied on for the protection against that hazard?

Does the chapter provide the basic operational modes used by the facility that are relevant to the derivation of the TSRs?

Savannah River Site (as approved) Implementing Guideline/Criteria

No additional requirements were identified in the SRS Implementing guidelines.

\section{APT (as approved) Safety Implementation PIan (Section 4.5)}

The SIP does not add additional requirements other than meeting the requirements established in DOE STD-3009-94.

\section{Chapter 6 Prevention of Inadvertent Criticality}

DOE-STD-3009-94. Pages 75-79

Does the chapter provide a summary of the overall site-specific, criticality protection policy and program? 
Does the chapter provide a description of the basis and analytical approach the facility will use for deriving operational criticality limits?

Does the chapter provide a summary of the design and administrative controls used by the criticality protection program.

Does the chapter identify the fissile material available within the facility and information on the location of potential criticality hazards, the fissile material form, and the maximum qualities involved?

Does the chapter provide a summary of the information relevant to criticality controls? This would include engineering controls, administrative controls, and the application of the double contingency principles.

Does the chapter provide an overview of the organizational structure and interfaces, and the technical and administrative practices of the criticality protection policy and programs? This includes providing a description of the criticality safety organization, the criticality safety $\mathrm{plans}$ and procedures, criticality safety training, the determination of operational nuclear criticality limits, the criticality safety inspection/audits, and the criticality infraction reporting and follow-up.

If required, does the chapter describe the criticality alarm and detection system used to mitigate exposures from a criticality event?

Savannah River Site (as approved) Implementing Guideline/Criteria

No additional requirements were identified in the SRS Implementing guidelines.

APT (as approved) Safety Implementation Plan (Section 4.7)

According to the SIP, this Chapter does not apply to the APT. 
However, the Chapter numbering system will be retained to comply with DOE STD-3009-94.

\subsubsection{Site Characteristics and Cleanup Chapters}

The APT ISRC considers chapters 1,2 and 16 to be the site characteristic and cleanup chapters for purposes of the APT PSAR review, and preparation of the SER. The topic and sub-topics of each of these chapters represent the background to be used for the APT's accident analysis and the systems incorporated into the design to facilitate the plant cleanup. It is considered the responsibility of the PSAR preparer to demonstrate that the design basis for each topic and sub-topic achieves a safe operating environment.

\section{Chapter 1, Site Characteristics}

DOE-STD-3009-94, Pages 23-26

Does the chapter provide an introduction to the contents of the chapter based on the graded approach and include objectives and scope specific to the chapter as developed?

Does the chapter 1 ist the design codes, standards, regulations, and DOE Orders which are required for establishing the safety basis of the facility?

Does the chapter describe and identify the site boundary and facility area boundary in sufficient detail to determine the proximity to the public, other facilities and the point where the Evaluation Guidelines are applied?

Does the chapter provide basic geographic information, including:

State and country in which the site is located.

Location of the site relative to prominent natural and manmade features, such as rivers, lakes, mountain ranges, dams, airports, population centers.

General location map to define the boundary of the site and 
show the correct distance of significant facility features from the site boundary.

Public exclusion areas and access control areas.

Identification of the point where Evaluation Guidelines are applied.

Additional detail maps, as needed, to present near plant detail, such as orientation of buildings, traffic routes, transmission lines, and neighboring structures.

Does the chapter provide population information based on recent census data showing the population distribution as a function of distance and direction from the facility for worker populations and nearby residences, major population centers, and major institutions such as schools, hospitals, etc., as defined by the area significantly affected by the accidents analyzed in Chapter 3, "Hazard and Accident Analyses?"

Does the chapter provide the meteorological information necessary to understand the regional weather phenomena of concern for facility operation and to understand the dispersion analyses performed?

Does the chapter provide the hydrological information necessary to understand any regional hydrological phenomena of concern for facility operation, and to understand any dispersion analyses performed, including the average and extreme conditions as determined by historical data to meet the intent of this section?

Does the chapter provide the geological information necessary to understand any regional geological phenomena of concern for facility operation, including a description of the nature and results of investigations performed?

Does the chapter provide an identification of specific natural phenomena events, such as design basis earthquakes considered to be potential accident initiators? 
Does the chapter provide a summary of the assumptions supporting the analysis in.Chapter 3, "Hazard and Accident Analyses?"

Does the chapter identify the specific external man-made phenomena associated with the site--events such as explosions from natural gas lines or accidents from nearby transportation activities-considered to be potential accident initiators, exclusive of sabotage and terrorism?

Does the chapter provide a summary of the assumptions supporting the analysis in Chapter 3, "Hazard and Accident Analyses?"

Does the chapter identify andy nearby facilities that could be affected by accidents within the facility being evaluated and facilities onsite or offsite that could adversely impact the facility under evaluation?

Does the chapter provide an assessment of the validity of site characteristic assumptions for existing environmental analyses and impact statements based on the more recent SAR effort.

\section{Savannah River Site (as approved) Implementing Guideline/Criteria}

No additional requirements were identified in the SRS Implementing guidelines.

\section{APT (as approved) Safety Implementation PTan (Section 4.2)}

Does the chapter utilize site characterization data which are consistent with the APT site selection document and the SRS site specific Environmental Impact Statement?

\section{Chapter 2 - Facility Description}

DOE-STD-3009-94, pages 27-29

Does the chapter provide an introduction to the contents of this chapter based on the graded approach and include objectives and scope specific to the chapter as developed? 
Does the chapter list the design codes, standards, regulations, and DOE Orders which are required for establishing the safety basis of the facility?

Does the chapter provide a brief overview of the current and historical use of the facility, projected future uses, facility configuration, and the basic processes performed therein?

Does the chapter provide an overview of the basic facility buildings and structures, including construction details such as basic floor plans, equipment layout, construction materials, controlling dimensions, and dimensions significant to the hazard and accident analysis activity?

Does the chapter provide a description of the individual processes within the facility and basic process parameters, including summary of types and quantities of hazardous materials, process equipment, instrumentation, control systems and equipment, basic flow diagrams, and operational considerations associated with individual processes or the entire facility, including major interfaces and relationships between SSCs?

Does the chapter provide the necessary supply information to normal operations, the safety analysis and its conclusions, and provide insight into the types of operations for which a safety management program must be devised?

Does the chapter identify and describe the set of structures, systems, and components that perform confinement functions such as process vessels, glove boxes, ventilation systems, and facility walls?

Does the chapter identify and describe the principal systems that perform safety support functions, including purpose of each system and an overview of each system, including principal components, operations, and control function?

Does the chapter provide a schematic outline of the basic utility distribution systems, including a description of the offsite power supplies and onsite components of the system? 
Does the chapter provide the information on the remaining portions of the facility that have not been covered by the preceding sections which are necessary to create a conceptual model of the facility as it pertains to the hazard and accident analyses?

\section{Savannah River Site (as approved) Implementing Guideline/Criteria}

No additional requirements were identified in the SRS implementing guidelines.

\section{APT (as approved) Safety Implementation Plan (Section 4.3)}

Does the chapter provide the basis to understand the hazard and accident analysis based on information contained in the FDD and SDDs?

\section{Chapter 16. Provisions for Decontamination and Decommissioning}

\section{DOE-STD-3009-94, Pages 121-122}

Does the chapter provide an introduction based on the graded approach and include objectives and scope specific to the chapter as developed?

Does the chapter 1 ist the design codes, standards, regulations, and DOE Orders which are required for establishing the safety basis of the facility?

Does the chapter provide a description of design features and operational considerations to facilitate future D\&D?

Does the chapter provide a summary of the conceptual plans for D\&D which documents that planning of operations and design or modifications minimizes the potential for spread of contamination that would complicate or reduce effectiveness of future $D \& D$ or environmental restoration activities?

Does the chapter provide an evaluation which considers the vulnerabilities to normal and abnormal events and operational plans to minimize contamination and prevent an increase in 
residual risk during or after decommissioning in a manner similar to the hazard analysis described in Section 3.3, "Hazard Analysis"?

Savannah River Site (as approved) Implementing Guidelines/Criteria

No additional requirements were identified in the SRS implementing guidelines.

APT (as approved) Safety Implementation Plan (Section 4.17)

To be developed.

\subsubsection{Programmatic Chapters}

The APT ISRC considers Chapters 7 through 15, and 17 to be the programmatic chapters for purposes of the APT PSAR review, and preparation of the SER. The topic and sub-topics of each of these chapters represent the APT's implementation by design, therefore, each has the potential of affecting safety in an adverse manner. Given the ISRC's interest in safety over mission, efficiency, and cost, the following chapter-by-chapter criteria will be used to verify that each topic and sub-topic representing an as-designed feature of the APT is "safe." It is considered the responsibility of the PSAR preparer to demonstrate that the design basis for each topic and sub-topic achieves a safe operating environment.

Each set of criteria is based on guidelines set forth in DOE-STD-3009-94 as further refined by Savannah River Site guidelines and criteria (as approved) and the APT Safety Implementation Plan (as approved).

General provisions of DOE-STD-3009-94 for programmatic chapters of the APT PSAR that will apply pertain to:

graded approach considerations for a Hazard Category 2 (target/blanket, Tritium separation system) and a Hazard Category 3 (linear accelerator, baiance of plant) facility. That is, safety-management programs that control and 
discipline safety significant structures, systems, and components (SSCs) and processes; and

graded approach considerations for a Hazard Category 2 and 3 facility directed toward defense in-depth and worker safety.

\section{Chapter 7, Radiation Protection Criteria}

\section{DOE-STD-3009-94, Pages $81-85$}

Does the chapter provide a summary of the design of the radiation protection program and organization, in sufficient detail, to assess its impact on the Chapter 3 hazards and accident analysis?

Does the chapter provide a summary of the radiological policy and program design in sufficient detail to assess the impact on the Chapter 3 hazards and accident analysis?

Does the chapter describe radiation exposure controls including administrative limits, radiological practices, dosimetry, and respiratory protection design in sufficient detail to assess the impact on the Chapter 3 hazards and accident analysis?

Does the chapter provide a summary of the radiological monitoring design to protect the workers, and public, and the environment in sufficient detail to assess the impact on the Chapter 3 hazards and accident analysis?

Does the chapter provide a summary of the radiological protection instrumentation design in sufficient detail to assess the impact on the Chapter 3 hazards and accident analysis?

Does the chapter provide a summary design of the $\mathrm{plan}$ and procedures for maintaining records of radiation sources, releases, and occupational exposures?

Does the chapter explicitly demonstrate either by independent calculations or by means of direct reference to the hazards and accident analysis reported in Chapter 3 that Radiation Protection as designed measures are within maximum worker and if appropriate, 
the co-located workers or the public exposure limits for a Hazard Category 2 and 3 facility?

\section{$\underline{\text { Savannah River Site (as approved) Implementing Guideline/Criteria }}$}

Does the chapter fully comply with Section H2 of the SRS Hazard Analysis Methodology Manual WSRC-IM-97-9 for Radiological Control?

\section{APT (as approved) Safety Implementation Plan}

No additional requirements are identified in the APT SIP.

\section{Chapter 8, Hazardous Material Protection}

DOE-STD-3009-94. Pages 87-92

Does the chapter provide a summary of the hazardous material protection program and organization design in sufficient detail to assess its impact on the Chapter 3 hazards and accident analysis?

Does the chapter provide a summary of the hazardous material ALARA policy and program design in sufficient detail to assess its impact on the Chapter 3 hazards and accident analysis?

Does the chapter describe the hazardous material exposure control including identification of hazardous material, administrative limits, occupational medical programs, and respiratory protection design in sufficient detail to assess their impact on the chapter 3 hazards and accident analysis?

Does the chapter provide a summary of the hazardous material monitoring design to protect workers, the public, and the environment in sufficient detail to assess its impact on the Chapter 3 hazards and accident analysis?

Does the chapter provide a summary of the hazardous material protection instrumentation in sufficient detail to assess its impact on the Chapter 3 hazards and accident analysis? 
Does the chapter provide a summary of the design of the plan and procedures for maintaining hazardous material records, hazard communications, and occupational exposures?

Does the chapter explicitly demonstrate either by independent calculations or by means of direct reference to the hazards and accident analysis reported in Chapter 3 that the design features associated with the Hazardous Material Protection protect the workers (and if appropriate co-workers and public) risk does not exceed maximum limits for a Hazard Category 2 and 3 facility?

\section{Savannah River Site (as approved) Implementing Guideline/Criteria}

Does the chapter demonstrate that the design fully support the ALARA considerations established in SRS ALARA Design

Considerations and Radiological Engineering Procedure Manual E7?

\section{APT (as approved) Safety Implementation Plan (Section 4.9)}

Does the chapter provide APT specific information supplementing hazardous material already provided in the SRC generic SAR?

\section{Chapter 9, Radioactive and Hazardous Waste Management}

\section{DOE-STD-3009-94. Pages 93-96}

Does the chapter provide a summary of the radioactive and hazardous waste management and organization design in sufficient detail to assess its impact on the Chapter 3 hazards and accident analysis?

Does the chapter provide a summary of the site-specific radioactive, mixed, and hazardous material waste management policy, objectives, and philosophy in sufficient detail to assess its impact on the Chapter 3 hazards and accident analysis?

Does the chapter identify the anticipated hazardous waste streams, including types, sources, and quantities, in sufficient detail, to assess their impact on the Chapter 3 hazards and accident analysis? 
Does the chapter provide a summary of the waste management process, and waste treatment and disposal systems, including administrative controls design, in sufficient detail to assess its impact on the Chapter 3 hazards and accident analysis?

Does the chapter explicitly demonstrate either by independent calculations or by means of direct reference to the hazards and accident analysis reported in Chapter 3 that Radioactive and Hazardous Waste Management as designed features ensure that worker (and if appropriate co-workers and public) risk does not exceed maximum limits for a Hazard Category 2 and 3 facility?

\section{Savannah River Site (as approved) Implementing Guideline/Criteria}

No additional requirements are identified in the SRS guidelines.

\section{APT (as approved) Safety Implementation Plan (Section 4.10)}

Does the chapter contain information on each of the following topics?

- Radioactive and hazardous waste management program and organization

- Radioactive and hazardous waste streams and sources

- Waste management process

- Waste minimization

- Waste sources and characteristics

-- Waste handling or treatment systems

Chapter 10, Initial Testing, Inservice Surveillance, and Maintenance

DOE-STD-3009-94, Pages $97-100$

Does the chapter provide a summary of the facility initial testing program design in sufficient detail to assess its impact on the Chapter 3 hazards and accident analysis?

Does the chapter provide a summary of the facility in-service surveillance program design in sufficient detail to assess its impact on the Chapter 3 hazards and accident analysis? 
Does the chapter provide a summary of the facility planned, predictive, preventive, and corrective facility maintenance program designs in sufficient detail to assess their impact on the Chapter 3 hazards and accident analysis?

Does the chapter explicitly demonstrate either by independent calculations or by means of direct reference to the hazards and accident analysis reported in Chapter 3 that Initial Testing, Inservice Surveillance, and Maintenance as designed features ensure that worker (and if appropriate co-workers and public) risk does not exceed maximum limits for a Hazard Category 2 and 3 facility?

\section{Savannah River Site (as approved) Implementing Guideline/Criteria}

Does the chapter fully comply with Section H2 of the SRS Hazard Analys is Methodology Manual WSRC-IM-97-9 for Maintenance Management?

\section{APT (as approved) Safety Implementation Plan}

No additional requirements are identified in the APT SIP.

\section{Chapter 11, Operational Safety}

\section{DOE-STD-3009-94, Pages 101-103}

Does the chapter provide a summary of the conduct of operations design directly applicable to the facility, in sufficient detail, to assess its impact on the Chapter 3 hazards and accident analysis?

Does the chapter provide a summary of the features of the facility conduct of operations design, in sufficient detail, to assess its impact on the Chapter 3 hazards and accident analysis?

Does the chapter provide a summary of the facility fire protection programs design, in sufficient detail, to support their protection of the facility and the associated SSCs needed to perform safety functions? 
Does the chapter explicitly demonstrate either by independent calculations or by means of direct reference to the hazards and accident analysis reported in Chapter 3 that Operational Safety conduction of operations and fire protection program as designed features ensure that worker (and if appropriate co-workers and public) risk does not exceed maximum limits for a Hazard Category 2 and 3 facility?

Savannah River Site (as approved) Implementing Guideline/Criteria

Does the chapter fully comply with Section H2 of the SRS Hazard Analysis Methodology Manual WSRC-IM-97-9 for Operational Safety?

APT (as approved) Safety Implementation PIan (Section 4.12)

Does the chapter demonstrate which safety functions are to be controlled by an operator and which are to be automatic (machine activated)?

Does the chapter demonstrate that a single point management responsibility for operations and maintenance is being designed into the APT?

\section{Chapter 12, Procedures and Training}

DOE-STD-3009-94. Pages 105-107

Does the chapter provide a summary of the facility procedures and training program design in sufficient detail to assess its impact on the Chapter 3 hazards and accident analysis?

Does the chapter provide a summary of the processes by which the form and content of the procedures and training material will be developed, verified, and validated for normal, abnormal, and emergency operations; surveillance testing and maintenance?

Does the chapter describe the approach that will be used for maintaining written procedures, training materials, and records, in sufficient detail, to assess its impact on the Chapter 3 hazards and accident analysis? 
Does the chapter describe the approach that will be used for modifying written procedures, training materials, in sufficient detail, to assess its impact on the Chapter 3 hazards and accident analysis?

Does the chapter describe the approach that will be used to feed back operations experience, new analyses, other SAR changes, to the procedures and training programs, in sufficient detail, to assess its impact on the Chapter 3 hazards and accident analysis?

Does the chapter provide a summary of the mechanisms that will be used to identify and correct technical or human factors deficiencies?

Does the chapter explicitly demonstrate either by independent calculations or by means of direct reference to the hazards and accident analysis reported in Chapter 3 that Procedures and Training program as designed features ensure that worker (and if appropriate co-workers and public) risk does not exceed maximum limits for a Hazard Category 2 and 3 facility?

\section{Savannah River Site (as approved) Implementing Guideline/Criteria}

Does the chapter fully comply with Section H2 of the SRS Hazard Analysis Methodology Manual WSRC-IM-97-9 for Procedures and Training?

\section{APT (as approved) Safety Implementation Plan}

No additional requirements are identified in the APT SIP.

\section{Chapter 13, Human Factors}

\section{DOE-STD-3009-94. Pages 109-111}

Does the chapter provide a summary of the human factors approach that approach and process that will be used for systematically inquiring into the importance of human factors in facility safety, in sufficient detail, to assess its impact on the Chapter 3 hazards and accident analysis? 
Does the chapter provide a summary of the human factors interfaces with safety significant SSCs and safety-class SSCs that are important to safety?

Does the chapter describe the approach that will be used for systematic inquiry into the optimization of human-machine interfaces with safety significant SSCs and safety-class SSCs to enhance human performance?

Does the chapter explicitly demonstrate either by independent calculations or by means of direct reference to the hazards and accident analysis reported in Chapter 3 that worker risks attributable to human machine interface (Human Factors) as designed features ensure that worker (and if appropriate coworkers and public) risk does not exceed maximum limits for a Hazard Category 2 and 3 facility?

\section{Savannah River Site (as approved) Implementing Guideline/Criteria}

No additional requirements are identified.

\section{APT (as approved) Safety Implementation Plan}

No additional requirements are identified.

\section{Chapter 14, Quality Assurance}

DOE-STD-3009-94. Pages 113-115

Does the chapter provide a summary of the quality assurance program and organization design in sufficient detail to assess its impact on the Chapter 3 hazards and accident analysis?

Does the chapter provide a summary of the document control and records management program design in sufficient detail to assess its impact on the Chapter 3 hazards and accident analysis?

Does the chapter describe the design of the quality assurance process ensuring that performed safety related work meets 
requirements, in sufficient detail, to assess its impact on the Chapter 3 hazards and accident analysis results?

Does the chapter explicitly demonstrate either by independent calculations or by means of direct reference to the hazards and accident analysis reported in Chapter 3 that worker risks attributable to Quality Assurance as designed features ensure that worker (and if appropriate co-workers and public) risk does not exceed maximum limits for a Hazard Category 2 and 3 facility?

\section{Savannah River Site (as approved) Implementing Guideline/Criteria}

No additional requirements are identified.

\section{APT (as approved) Safety Implementation Plan (Section 4.15)}

Does the chapter clearly demonstrate that quality assurance principles and practices are being designed into the APT in accordance with 10 CFR 830.120 , DOE Order 5700.6C?

\section{Chapter 15, Emergency Preparedness Program}

DOE-STD-3009-94, Pages 117-120

Does the chapter provide a summary of the emergency preparedness plan (EPP) design in sufficient detail, to assess its impact on the Chapter 3 hazards and accident analysis results?

Does the chapter explicitly demonstrate either by independent calculations or by means of direct reference to the hazards and accident analysis reported in Chapter 3 that worker risks attributable to Emergency Preparedness as designed features ensure that worker (and if appropriate co-workers and public) risk does not exceed maximum limits for a Hazard Category 2 and 3 facility?

\section{Savannah River Site (as approved) Implementing Guideline/Criteria}

Does the chapter fully comply with Section H2 of the SRS Hazard Analysis Methodology Manual WSRC-IM-97-9 for Emergency 
Preparedness?

APT (as approved) Safety Implementation Plan

No additional requirements are identified.

\section{Chapter 17, Management, Organization, and Institutional Safety}

DOE-STD-3009-94, Pages 123-125

Does the chapter provide a summary of the design for the overall structure of the organizations and personnel with responsibilities for facility safety and interfaces between those organizations in sufficient detail, to assess its impact on the chapter 3 hazards and accident analysis results?

Does the chapter provide a summary of the design of the programs that will promote safety consciousness and morale, including safety culture, performance assessment, configuration and document control occurrence reporting, and staffing and qualifications, in sufficient detail, to assess its impact on the chapter 3 hazards and accident analysis results?

Does the chapter explicitly demonstrate either by independent calculations or by means of direct reference to the hazards and accident analysis reported in chapter 3 that worker risks attributable to Management, Organization and Institutional Safety as designed features ensure that worker (and if appropriate co-workers and public) risk does not exceed maximum limits for a Hazard Category 2 and 3 facility?

Savannah River Site (as approved) Implementing Guideline/Criteria No additional requirements are identified. 


\section{APT (as approved) Safety Implementation Plan}

No additional requirements are identified.

\section{SER Preparation and Assignments}

The SER will be prepared following requirements and guidelines in DOESTD-1104-96, Chapter 3. The purpose of the SER is to document that an appropriate review of the PSAR was conducted and to document the bases for approving the PSAR, including any conditions of approval that impose additional commitments to which facility management must adhere beyond those already documented in the PSAR. PSAR approval signifies that DOE has accepted the PSAR as appropriately documenting the safety basis of a facility.

Sections 7.1 through 7.6 of this chapter provide information identifying:

- SER Preparation Team Organization

- Process for Identifying SER Issues

- Acceptance Criteria to be Used in the SER

- SER Preparation, Review, and Approval Process

- Quality Assurance Requirements for the Preparation of the SER

- SER Content and Format Guidance.

\subsection{SER Preparation Team Organization}

The responsibilities of the various groups contributing to the preparation of the SER and the overall interfaces of these groups are discussed in Section 3 of this SRP and are briefly summarized herein.

The Review Team will prepare the draft SER based on the input from the Independent Reviewers prepared during their review and the resolution of issues from the APT Program Office. Once the draft SER is prepared, it is to be reviewed by a review panel consisting of DP-20 and SRS. Following the draft SER review, the comments are submitted to the APT Program Office. Any comments from the DNFSB will be given to the Program office at this time. Following the decision on what changes to the SER are required by the Program Office, the draft SER will be given to the Review Team for incorporation in the final SER. The Review Team will incorporate changes into the SER and issue the Final SER upon approval of the APT Program Office. 


\subsection{Process for Identifying SER Issues}

Identification of SER issues will be basically a refinement and consolidation of outstanding, significant comments on the PSAR. As described in Section 6.2 of the SRP, review comments on sections and sub-sections of each chapter of the APT PSAR will be in a standard format. Three levels of comments will be provided to the PSAR preparers. These levels include, significant, optional and editorial. The detail associated with each of these levels of comments is discussed in Section 6.2.1.

The SER is developed specifically to document acceptance of the PSAR. Therefore, significant issues concerning the PSAR are typically resolved and incorporated into the PSAR before the final SER is prepared. These resolutions are documented independently of the SER as part of the review process and thus do not require repetition in the SER. Any analysis that was not performed during PSAR preparation but is determined to be required to complete the review is also documented independently of the SER. Only statements pertinent to accepting the facility safety basis are included in the SER.

Approval statements addressing specific areas of the safety basis will be augmented with brief summaries of the most significant facility-specific points in those areas to provide a basic context to understand what is being approved. If the SER imposes a condition of approval (e.g., additional compensatory measures, alterations of stated commitments) on the facility safety basis documented in the PSAR, then the SER necessarily modifies that facility safety basis. In such cases, conditions cited in the SER become part of the facility safety basis.

\subsection{Acceptance Criteria to be Used in the SER}

The evaluation criteria to be used in the SER for each chapter of the PSAR are provided in Section 6.4 of this SRP. These criteria have been established by the guidance and requirements in DOE-STD-3009-94, SRS implementing guidelines, the APT SIP, and the governing requirements documents identified in each chapter of the PSAR. Major elements of the established criteria consist of description of the safety analysis/evaluation process, description of the hazard categorization, accident analysis and risk acceptance, safety equipment and features, safety classification, and general document quality. 


\subsection{SER Preparation, Review, and Approval Process}

The overall review process and organizational responsibilities for preparing the PSAR and SER are provided in Chapter 6 of this SRP and are summarized herein.

Preparation of the SER will be a continuing process. Immediately upon approval of the SRP work on the SER will begin. Descriptive sections of the SER will be prepared followed by a fitting of the evaluation sections into the SER shell on a continuing basis.

The draft report will be a comprehensive SER making the case that the APT as-designed safety basis, as documented in the PSAR, meets a 11 safety requirements established for the APT by cognizant Federal, state, and local jurisdictions. The SER format and content will conform to principles and provisions established in DOE-STD-1104-96, Sections 3.1 through 3.10.

\subsection{Quality Assurance Requirements for the Preparation of the SER}

The quality assurance requirements for the preparation of the SER are consistent with those identified for the systematic review of the APT PSAR, which are provided in Chapter 10 of this SRP. These requirements are in accordance with the LMITCO Record Management Program Requirements Document PRD-101.

\subsection{SER Content and Format Guidance}

The overall content of the SER shall be based on a graded approach as required by DOE-STD-1104-96 and described in DOE 5480.23. The SER shall be commensurate with the scope of the Safety Documentation. The SER addresses only those issues that are germane to documenting the basis of SAR acceptance; therefore the SER is subject to the graded approach. Summaries of material already contained in the APT PSAR should be brief but sufficient to provide a knowledgeable reader a basic understanding of the basis of approving that PSAR. The SER will be in the form of a formal report.

In general, the SER is expected to follow the format and content recommended in DOE-STD-1104-96, Sections 3.1 through 3.10. A brief summary is provided herein. 
The title page provides the unique identifier information for both the PSAR and the SER. Minimum information consists of: (1) SER title, revision number, and date issued; (2) PSAR title, revision number, and date issued; (3) facility name and identification number, if any; (4) site; and (5) DOE contractors name and appropriate contract number.

\section{Signature Page}

The signature page provides the identification and signature of the approval authority, and the date of PSAR approval. Non-concurrence or differing professional opinion by reviewer team members should be indicated and documented in an appendix to the SER. Other signatures may be provided at the discretion of the approval authority.

\section{Executive Summary}

This section is intended to provide an overall summary of the facility and the associated risks and to summarize the basis of PSAR approval. Because of the importance of this section in providing the results of the DOE review, it should be largely self contained with the following information, briefly summarized:

- identification of the facility for which PSAR approval is being granted and its hazard category;

- statement of the facility mission and scope of operations encompassed by the facility mission;

- summary of the major facility hazards and dominant accident scenarios;

- discussions of pertinent exemptions and/or consent agreements impacting the SAR approval;

- discussions of major mission- and project-related influences impacting the decision to authorize operation;

- any conditions of approval and/or open issues raised with regard to the five approval bases, including schedules for completion (if applicable). Include discussion of any team member nonconcurrence or differing professional opinion; and

- statement on the acceptability of the PSAR indicating that the PSAR has undergone an appropriate review and that the facility 
safety basis as documented is acceptable with stated conditions of approval, if any.

\section{Table of Contents}

\section{Review Process}

This section provides a brief description of the review process the PSAR has undergone and its basis. While discussion should be brief, sufficient information should be presented to provide an understanding of the thoroughness of the review process and its basis.

\section{Base Information}

This section documents the bases of approving the adequacy of base information, including any conditions of approval imposed. A statement of adequacy is generally focused and brief. In addition to bases of acceptance, this SER section provides a brief synopsis of major site, facility, and operational process features. This information is intended for the sole purpose of providing a minimal, facility-specific context for SER bases of approval, such that an elementary understanding of the operational envelope can be gleaned from the SER.

Hazard and Accident Analyses

This section documents the bases for approving the hazard and accident analyses, including any conditions of approval imposed. Such documentation focuses on the completeness of the analysis and the consistency of the logic used throughout the analysis process.

In addition to bases of acceptance, this SER section provides: (1) a brief synopsis of hazards identified; (2) fundamental aspects of defense in depth, worker safety, and environmental protection; (3) dominant accident potentials; and (4) accident consequences relative to DOE-STD-3009-94 Evaluation Guidelines.

Safety Structures, Systems, and Components 
This section documents the bases for approving the designation of safety SSCs and their associated safety functions, functional requirements, system evaluations, and potential TSR coverage, including any conditions of approval imposed. Focus is on the consistency of the logic developed in hazard and accident analyses being carried through to the identification of safety SSCs and the definitions and descriptions provided for these SSCS. In addition to bases of acceptance, this SER section provides a brief synopsis of safety SSCs and their safety functions as determined in the hazard and accident analyses.

\section{Derivation of Technical Safety Requirements}

This section documents the bases for approving the derivation of TSRS, including any conditions of approval imposed. Such documentation focuses on the consistency of the logic developed in the hazard and accident analyses and safety SSCS chapters being carried through to the derivation of TSRS. In addition to bases of acceptance, this SER section provides a brief synopsis of the derivation of TSRs as a function of the hazard and accident analyses.

\section{Programmatic Control}

This section documents the bases of approving programmatic control, including any conditions of approval imposed. These bases do not relate to compliance with regulatory requirements, but to identification of the basic capability and awareness of fundamental provisions needed for maintaining the adequacy of the facility safety basis.

\section{Records}

This section provides references to the essential records, documentation, and information generated throughout the review process. This may include reference to records of: (1) the PSAR review $p l a n$ and schedule; (2) minutes of review meetings, including meetings with the facility contractor; (3) dates and results of facility walkthroughs; (4) submittal of issues and their disposition; (5) documentation generated in resolution of issues; and (6) documentation regarding commitments made by the facility contractor for PSAR approval. 


\section{Milestone Schedule}

The major milestone schedule for the performance of the independent review of the PSAR and the preparation of the SER is provided in Table 8-1.

\section{Profiles of PSAR Review and SER Preparation Participants}

The ISRC reviews will be conducted in accordance with a broad range of requirements and safety criteria contained in Public Laws, rules, orders, standards, and guidelines established by Federal, state, and local governments with jurisdiction over the APT facility. Also, by professional organization standards and guidelines endorsed by these governments.

In order to conduct complete and non-partisan reviews of the APT PSAR it is first necessary to ensure that collectively the review teams have a complete knowledge of the aforementioned requirements and safety criteria, and how these requirements and safety criteria apply to the as designed APT. Secondly, it is necessary that collectively the review teams have knowledge of and experience with the technologies making up the APT. Finally, it is necessary that collectively the review teams have a thorough understanding of and experience with the safety analys is techniques that are applied to the as designed APT to demonstrate its margin of safety.

To achieve such a review capability, the APT ISRC brings together engineers and scientists from the Department of Energy, Idaho National Engineering and Environmental Laboratory, and AMPARO Corporation. Figure 3.1 presents the APT organizational structure including inter and intra ISRC interfaces. The three-level internal organization of the ISRC provides for check and balances to ensure that a complete knowledge of APT requirements and safety criteria, technologies, and safety analysis techniques is brought to each review. Table 6.1 lists, by PSAR chapter, personnel from each source who make up each chapter review team. 
Table 8-1 Milestone Schedule

\begin{tabular}{|c|l|c|c|}
\hline Item No. & \multicolumn{1}{|c|}{ Description } & Start & Finish \\
\hline 1 & $\begin{array}{l}\text { Prepare Safety Review } \\
\text { Plan }\end{array}$ & June 8, 1997 & Sept 10 1997 \\
\hline 2 & Review of PSAR Chapters & Aug 18,1997 & May 8, 1998 \\
\hline 3 & $\begin{array}{l}\text { Initial Draft of SER } \\
\text { plus revisions }\end{array}$ & May 5 1998 & $\begin{array}{c}\text { Aug 6, 1998 } \\
\text { (Issue) }\end{array}$ \\
\hline 4 & Final SER & Sept 23,1998 & $\begin{array}{c}\text { 0ct 16, 1998 } \\
\text { (Issue) }\end{array}$ \\
\hline 5 & $\begin{array}{l}\text { Safety Implementation } \\
\text { Plan preparation }\end{array}$ & Mar 17,1997 & Aug 15, 1997 \\
\hline 6 & $\begin{array}{l}\text { Recommendation for } \\
\text { Construction Approval* } \\
\text { (Review Panel) }\end{array}$ & Oct 26,1998 & Dec 28, 1998 \\
\hline 7 & $\begin{array}{l}\text { Approving Official Start } \\
\text { of Construction Approval }\end{array}$ & Dec 28,1998 & Dec 29, 1998 \\
\hline
\end{tabular}

Start of Construction of the APT is defined following the NRC guidance provided in 10 CFR 50.10 for nuclear facilities as "to include the pouring of foundations for, or the installation of, any pouring of the permanent facility on the site, but does not include: 1) site exploration, site excavation, preparation of the site for construction of site for construction of the facility, including of driving of the piles, and construction of railroads, railroad spurs, and transmission lines; 2) Procurement or manufacture of components of the facility; 3 ) Construction of non-nuclear facilities and temporary buildings for use in connection with the construction of the facility." It further states that "commencement of construction means any clearing of land, excavation or substantial action that would adversely affect the enviroment of the site, but does not mean: 1) Changes desirable for the temporary use of the land for public recreational uses, necessary borings to determine foundation conditions or other preconstruction monitoring to establish background information related to the suitability of the site or to the protection of environmental values; and 2) Procurement or manufacture of components of the facility." In any event, any excavation for the APT should be in conformance with the approved EIS.

\section{Record Keeping}

The record keeping requirement for the Independent Safety Review of the APT PSAR is accordance with LMITCO Record Management Program Requirements Document PRD-101. The comment and resolution records generated during the review will be recorded on the Comment/Resolution Form shown in Figure 6-2. The description of what is required to fill out the form and how the form is 
to be processed is contained in Section 6.2. Once the Review Team signs off on the comment/resolution form, the information contained on the form becomes a record. At this point the record must meet the records management requirements.

The following records requirements must be met during the generation, storage and disposal of records associated with the APT Independent Safety Review:

Generation of Records - Implementing documents shall identify those documents that will become records. The individual creating documents that are to become records shall ensure that they are legible, accurate, complete appropriate to the work accomplished, and identifiable to the activity to which they apply.

Record Validation - Documents shall be considered records only if the authenticated and dated by the authorizing individual or group.

Index - Records shall be indexed to ensure retrievability. The indexing shall include: a) the location of the record within the records management system; b) the activity to which the record pertains; c) the record retention time; and d) the classification of the record.

Distribution - Records shall be distributed according to written procedures.

Identification - Records and the indexing system shall have sufficient information between the record and the activity to which it applies.

Classification - Records shall be classified as to lifetime or nonpermanent. The APT records shall be a lifetime record.

Records Retention - Records shall be retained in accordance to the above classification.

Corrected Information in Records - Corrections to records shall include the initials or signature of the person authorized to make the corrections and the date the corrections were made. 
Receipt - A person shall be assigned for receiving the records and shall be responsible for organizing and implementing the control of records for permanent and temporary storage.

Status - The receipt control system shall permit a current and accurate assessment of the status of the records.

Storage - The records shall be stored in locations that meets the requirements of the applicable standards, codes, and regulatory agencies.

Preservation - The records shall be stored in a manner that preclude the deterioration of the records.

Safekeeping - Measures shall be established to preclude the entry of unauthorized personnel in the storage area. These measures shall guard against 1 arceny and vandalism.

Storage Facilities - Records shall be stored in facilities constructed and maintained in a manner which minimizes the risk of damage and destruction from: natural disasters (fire, wind, or floods); environmental conditions (temperature and humidity); and infestations of insects, molds, or rodents.

Retrieval - The storage system shall provide for retrieval of information based on the retrieval times based on the record type. Access control shall be maintained to only people permitted to have access.

Disposition - Records management shall have schedules for records retention and disposition in accordance with the requirements of the National Archives and Records Administration.

The management of the records will be in accordance with the requirements established in LMITCO PRD-101, and implementing procedure MCP 557.

The comment/resolution is not considered a record until the comments are signed off by the Review Team. At this point in time the configuration management requirements for records will be initiated. Prior to that time the 
in-process configuration management will be enforced which requires routine office procedures for the control and disposition of the documents.

\section{Reports}

Several types of reports will be prepared on an as needed basis to keep internal ART project participants and external oversight organizations fully apprised of the status and findings of the ISRC. Reports will include minutes, memoranda, informal review/evaluation reports of analyses, Technical Evaluation Reports (TERs), and inputs to the draft SER.

\subsection{Meeting Minutes}

There will be numerous review/discussion meetings directed, at least in part, to matters pertaining to the independent safety review. Within 10 working days after attendance by ISRC team members at a APT program meeting, a written set of meeting minutes will be provided to the APT program office. The minutes will identify the meeting purpose, date(s), location, and attendees. Subsequently, it will identify each issue raised during the meeting pertaining to the independent safety review process and resolution of the issue achieved during the meeting, if appropriate. Finally, the minutes will list action items for which the ISRC team is responsible and anticipated dates of completion. All communications from the ISRC team to project participants will be through the APT safety Approving Authority as advised in DOE-STD-1104-96.

\subsection{Formal Technical Evaluations}

The ISRC will provide feedback to the safety documentation authors in a manner that can be understood and responded to by the authors, and that can be used by the APT program office to make decisions affecting the APT program. To achieve this goal, a standard Technical Evaluation Report (TER) format will be used for reporting formal evaluations. A formal evaluation is defined here as one responding to a specific interim or final safety documentation submittal made in accordance with the standing APT program milestone schedule. Each of these formal reports will be in accordance with the principles and provisions established in or referenced by DOE-STD-1104-96, Section 2.1 through 2.5. Each formal technical evaluation report will be prepared in accordance with the following topical outline, as a minimum. 


\author{
Cover page \\ Abstract \\ Table of contents \\ Introduction \\ Body \\ Problem studied \\ Method of analysis \\ Results \\ Conclusions \\ Summary \\ References \\ Appendices
}

\title{
11.3 Informal Technical Evaluations
}

The ISRC will also provide feedback to the safety documentation authors on partial submittals, not part of the formal APT program milestone schedule. In these instances, the format and content of the feedback will be determined between the authors and the reviewers. It is anticipated that in most cases a inemorandum for the record will be prepared describing the review conducted, and summaries of findings, conclusions, and recommendations. As with the TER, copies of the memoranda for record will be provided in parallel to the safety documentation authors and APT program office.

\subsection{Periodic Progress Reports}

In order to maintain the technical and fiscal status of the independent review function visible to cognizant APT program sponsors and managers, a bimonthly progress report will be prepared. Each bi-monthly report will contains sections reporting on the following.

Purpose of Project (including milestones and goals for the period being reported on)

Accomplishments for the Reporting Period (relative to milestones and goals scheduled) 
Issues/Problems/Action Items (outstanding at the end of the reporting period)

Plans for the Next Reporting Period (including milestones and goals for the next period)

Table of Accomplishments (milestone table listing the status of milestone relative to schedule [not started, in-process, completed])

Planned Versus Actual Costs (relative to percentage of technical work accomplished. This latter information is important to track progress with expenditures.)

Attachments (correspondence, reports, etc., relating to milestones and goals reported in the bi-monthly progress report that may not be available from other sources)

\subsection{Draft SER}

This draft report will be a comprehensive SER making the case that the APT as-designed safety basis, as documented in the PSAR, meets all safety requirements established for the APT by cognizant Federal, state, and local jurisdictions, and as further defined in the APT Safety Implementation Plan (as approved). The SER format and content will conform to principles and provisions established in DOE-STD-1104-96, Sections 3.1 through 3.10.

Preparation of the SER wi11 be a continuing process. Immediately upon approval of the SRP work on the SER will begin. Descriptive sections of the SER will be prepared followed by a fitting of the evaluation sections into the SER shell on a continuing basis.

The initial draft of the complete and final version of the SER will be issued in accordance with the Milestone Schedule in Section 8 . These delivery dates assume that PSAR and TSR documents are available for review at least 3045 days prior to the proposed delivery dates. 
DOE Order 420.1: DOE, Facility Safety, October 13, 1995

DOE Order 5480.23: DOE, Nuclear Safety Analysis Reports, April 10, 1992

DOE Order 5480.25: DOE, Safety of Accelerator Facilities, November 3, 1992

DOE-STD-1020: DOE, Natural Phenomena Hazards Design and Evaluation Criteria for Department of Energy Facilities, April 1994

DOE-STD-1021: DOE, Natural Phenomena Hazards Performance Categorization Guidelines for Structures, Systems, and Components, December 1992

DOE-STD-1027-93: DOE, Guidance on Preliminary Hazard Classification Guidelines and Accident Analysis Techniques for Compliance with DOE Order 5480.23, Safety Analysis Reports, October 1992

DOE-STD-1104-96: DOE, Review and Approval of Nonreactor Nuclear Facility Safety Analysis Reports, February 1996

DOE-STD-3009-94: DOE, Preparation Guide for U.S. Department of Energy Nonreactor Nuclear Facility Safety Analysis Reports, July 1994

LMITCO PRD-101: Lockheed Martin Idaho Technologies Company, Program Requirements Document, Chapter 6 Records Management, Current Issue

MCP 557:

Lockheed Martin Idaho Technologies Company, Managing Records, Current Issue

SRS E-7:

Westinghouse Savannah River Company, SRS Procedural Manual E-7, Conduct of Engineering and Technical Support (U), May 25, 1993

WSRC-TM-93-9: Westinghouse Savannah River Company, Functional 
Classification Methodology Manual, WSRC-TM-93-9, Rev 3, March 3, 1995

WSRC-IM-97-9: Westinghouse Savannah River Company, Hazards Analysis Methodology Manual (U) WSRC-IM-97-9, March 20, 1997

SRS 11-Q: $\quad$ Westinghouse Savannah River Company, SRS Procedural Manual 11-Q, Westinghouse Savannah River Company Administrative and Procedural Controls System for SRS Reactor and Nonreactor Nuclear Facilities (U), July 19, 1996

GSAR:

Westinghouse Savannah River Company, Savannah River Site Generic Safety Analysis Report (U), G-SAR-G-0024, September 1995 
Attachment 1

Independent Review Process 


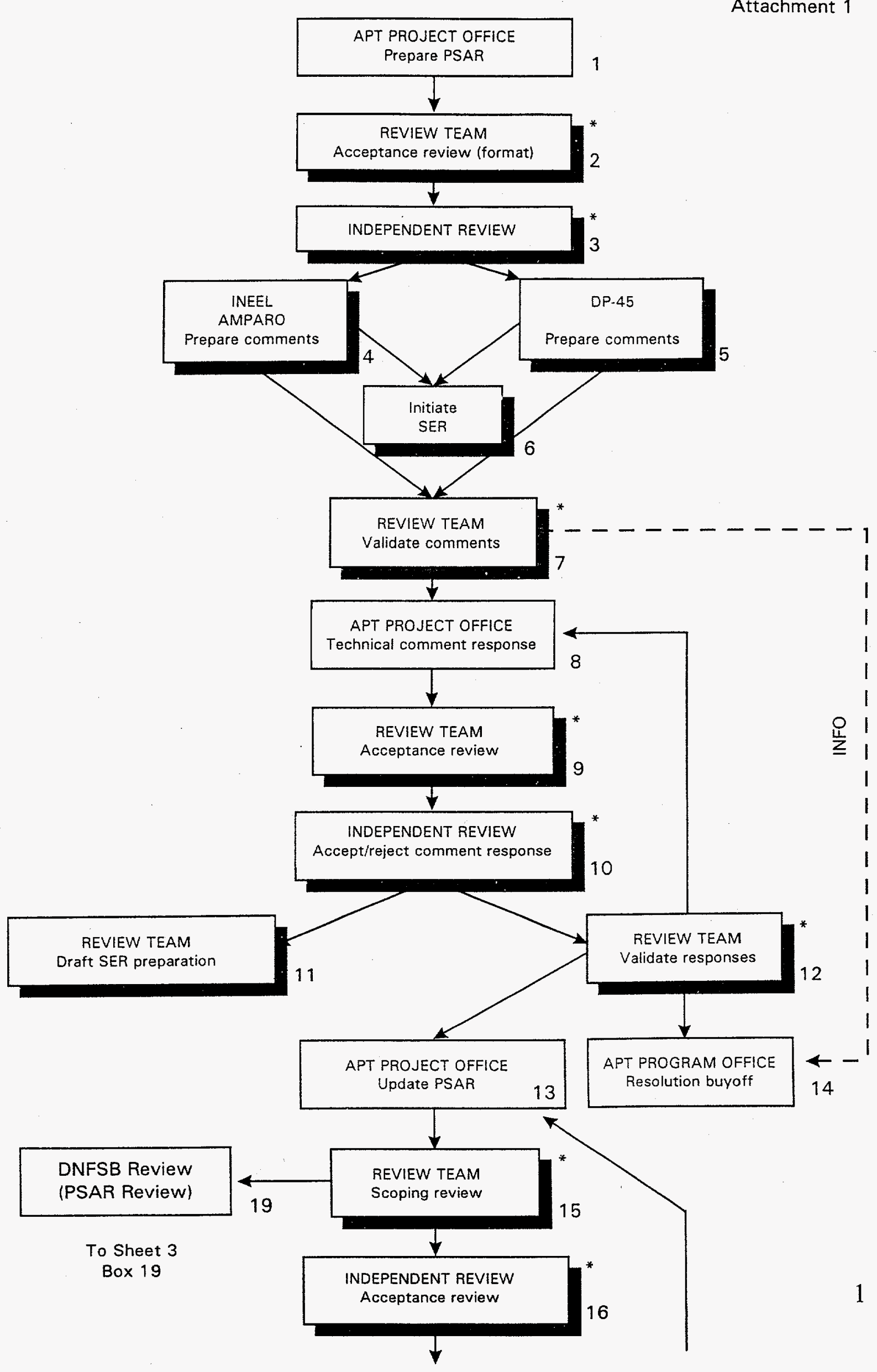



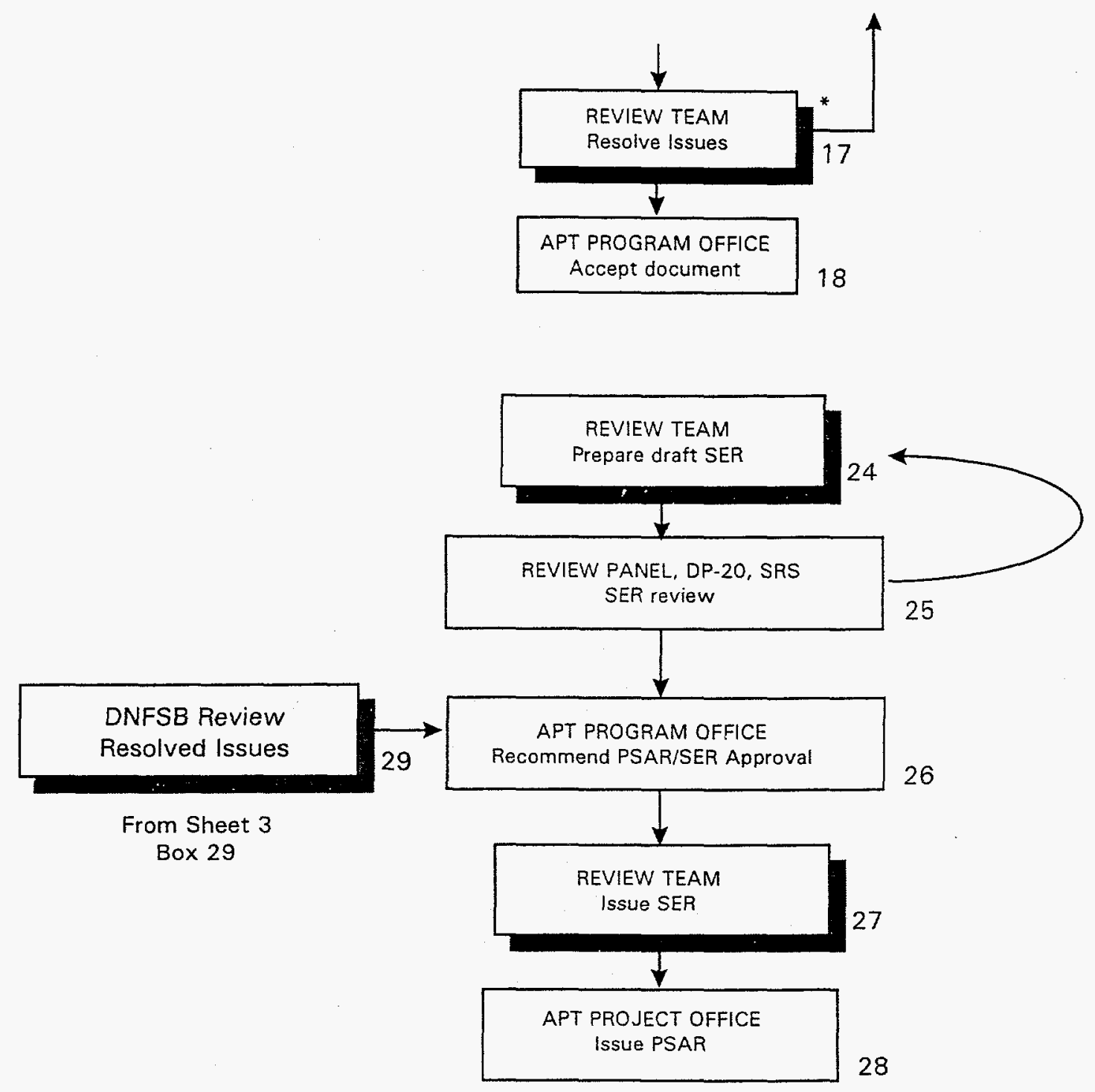

* Need acceptance criteria developed to determined go/no go status. Also what steps to be taken in the event of a no go determination. 


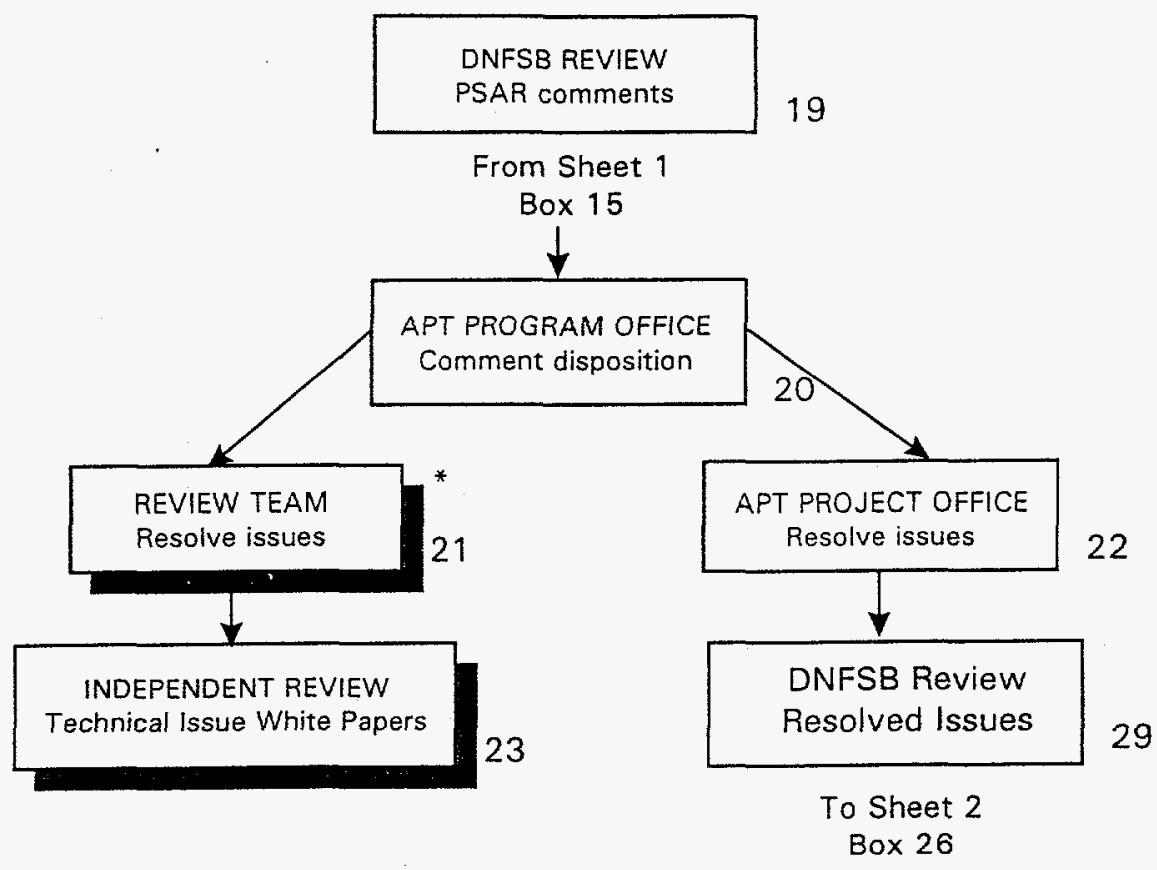

